\author{
José L. Gasche \\ Emeritus Member, ABCM \\ gasche@dem.feis.unesp.br \\ Department of Mechanical Engineering \\ Universidade Estadual Paulista - UNESP \\ Av. Brasil Centro 56 \\ 15385-000 Ilha Solteira, SP, Brazil
}

\section{Carbon Dioxide Evaporation in a Single Microchannel}

Despite its importance for designing evaporators and condensers, a review of the literature shows that heat transfer data during phase change of carbon dioxide is very limited, mainly for microchannel flows. In order to give a contribution on this subject, an experimental study of $\mathrm{CO} 2$ evaporation inside a $0.8 \mathrm{~mm}$-hydraulic diameter microchannel was performed in this work. The average heat transfer coefficient along the microchannel was measured and visualization of the flow patterns was conducted. A total of 67 tests were performed at saturation temperature of $23.3^{\circ} \mathrm{C}$ for a heat flux of $1800 \mathrm{~W} /\left(\mathrm{m} 2{ }^{\circ} \mathrm{C}\right)$. Vapor qualities ranged from 0.005 to 0.88 and mass flux ranged from 58 to $235 \mathrm{~kg} /(\mathrm{m} 2 \mathrm{~s})$. An average heat transfer coefficient of $9700 \mathrm{~W} /\left(\mathrm{m} 2{ }^{\circ} \mathrm{C}\right)$ with a standard deviation of $35 \%$ was obtained. Nucleate boiling was found to characterize the flow regime for the test conditions. The dryout of the flow, characterized by the sudden reduction in the heat transfer coefficient, was identified at vapor qualities around 0.85. Flow visualization results showed three flow patterns. For low vapor qualities (up to about 0.25), plug flow was predominant, while slug flow occurred at moderated vapor qualities (from about 0.25 to 0.50). Annular flow was the flow pattern for higher vapor qualities.

Keywords: Carbon dioxide, microchannel, evaporation, flow pattern, heat transfer coefficient

\section{Introduction}

It is widely known that the synthetic halocarbons used in refrigerating and air-conditioning systems are now phased out owing to their negative impact on the global environment. Promising alternatives for refrigeration technology are substances called by natural fluids, because of their negligible global warming potential (GWP). Among these fluids one can mention refrigerants like the hydrocarbons, ammonia, and carbon dioxide. If non-toxic and non-flammable fluid is required, carbon dioxide $\left(\mathrm{CO}_{2}\right)$ is a competitive refrigerant and has gained much attention recently. ${ }^{1}$

In addition to this environmental benefit, $\mathrm{CO}_{2}$ has excellent thermo physical properties. It has a much smaller surface tension and liquid viscosity. In consequence, bubble formation is facilitated due to the decreased surface tension, resulting in higher boiling heat transfer coefficient, while smaller pressure drop can be found due to the decreased liquid viscosity. The properties of the critical point $\left(31^{\circ} \mathrm{C}\right.$ and $74 \mathrm{bar}$ ) indicate that the pressure level is far higher in $\mathrm{CO}_{2}$ systems than in conventional systems, which has the disadvantage of requiring the development of suitable components. On the other hand, the high-pressure level permits the design of systems with small component dimensions and low compression ratios, which improve compressor efficiency.

As examples mentioned by Cavallini (1996), carbon dioxide has been successfully used in a prototype automotive air conditioner (an application with high direct global warming impact when using HFC134a), and excellent prospects are also predicted in commercial refrigerating units with associated tap-water heating, and in hightemperature-range heat pumps.

Associated with the compactness resulted from the use of $\mathrm{CO}_{2}$ as working fluid, the use of the microchannel technology (channel having hydraulic diameter of less than $2 \mathrm{~mm}$ ) in the heat exchangers design yields to very compact and lightweight equipments. The high heat transfer coefficients and significant potential in decreasing the heat exchanger surface area are the major advantages of using this kind of geometry. For these reasons microchannel heat exchangers have been used in bioengineering and microeletronics as well as in evaporators and condensers of refrigeration systems.

Paper accepted October, 2005. Technical Editor: Aristeu da Silveira Neto.
Regarding to the refrigeration systems application, the heat transfer performance of the evaporator is one of the important features of the successful operation of the refrigeration unit. Since the optimum design of the evaporator depends on the correct evaluation of the heat transfer characteristics of the flow during the phase change of the refrigerant, the knowledge of data on two-phase flow and heat transfer is essential.

Studies on two-phase flow and heat transfer in microchannel geometries have mostly been focused on low-pressure refrigerants, and air/water systems at atmospheric pressure. Even for conventional fluids, the knowledge on microchannel flow and heat transfer is limited, Pettersen (2001). There are few previous works on systematic experimental investigation of carbon dioxide heat transfer and its modeling.

Good reviews of microchannel heat transfer can be found in Zhao et al. (2000), Pettersen (2001), and Palm (2001). Zhao et al. (2000) presented a review of microchannel heat transfer for singlephase and two-phase (condensation and evaporation) forced convection. In this work they presented a short review of $\mathrm{CO}_{2}$ heat transfer, from which one can conclude that most authors have studied $\mathrm{CO}_{2}$ heat transfer for channels of large diameters (from about 5 to $11 \mathrm{~mm}$ ). In this review the authors commented that only Pettersen et al. (1998) had experimentally evaluated the overall heat transfer coefficient in microchannel heat exchanger. Zhao et al. (2000) also performed a series of experiments to study flow boiling of $\mathrm{CO}_{2}$ in microchannels. The experiments were conducted to investigate the effect of mass flux and heat flux on the boiling heat transfer coefficient and pressure drop. The experiments were conducted for mass flux from 250 to $700 \mathrm{~kg} /\left(\mathrm{m}^{2} \mathrm{~s}\right)$, heat flux from 8 to $25 \mathrm{~kW} / \mathrm{m}^{2}$, and saturation temperatures from 5 to $15^{\circ} \mathrm{C}$. The inlet vapor quality of all tests was 0.05 . They did not present the dimensions of the microchannel used. The preliminary results showed that the effects of mass flux and heat flux on heat transfer coefficient were negligible. It was also found that the thermalhydraulic performance of $\mathrm{CO}_{2}$ was superior to R134a.

Pettersen (2001) presented a good review on $\mathrm{CO}_{2}$ evaporation heat transfer and pressure drop for large-diameter flow as well as for microchannel flow. He mentioned that earlier studies on $\mathrm{CO}_{2}$ evaporation heat transfer for large diameter flow were performed by Bredesen et al. (1997), Hogaard Knudsen and Jensen (1997), Rieberer (1998), Sun and Groll (2001), and Yun et al. (2001). On microchannel flow, heat transfer data for $\mathrm{CO}_{2}$ were obtained by Hihara and Tanaka (2000), Zhao et al. (2000), Ohadi et al. (2000), and Koyama et al. (2001). Pettersen (2001) commented that the 
results presented by these authors were obtained by different experimental methods and for various operational conditions and have shown certain discrepancies among the data. Pettersen (2001) also conducted heat transfer tests in a rig using a flat, extruded aluminum microchannel tube of $540 \mathrm{~mm}$ length with 25 channels of $0.81 \mathrm{~mm}$ diameter. The test tube was heated by water jacket in order to get representative boundary conditions for air-to-refrigerant heat transfer ("fluid heating"). Evaporation heat transfer and pressure drop data were recorded over a wide range of conditions, including temperatures from 0 to $25^{\circ} \mathrm{C}$, heat flux from 5 to $20 \mathrm{~kW} / \mathrm{m}^{2}$, mass flux from 190 to $570 \mathrm{~kg} /\left(\mathrm{m}^{2} \mathrm{~s}\right)$, and vapor qualities between 0.2 and 0.8. Test results showed that the nucleate boiling mechanism dominated at low/moderate vapor qualities, where the heat transfer coefficient increased with heat flux and temperature, but was less affected by varying mass flux and vapor fraction. Heat transfer coefficients ranging from about 10 to $20 \mathrm{~kW} /\left(\mathrm{m}^{2}{ }^{\circ} \mathrm{C}\right)$ were measured in this region. Dryout effects became very important at higher mass flux and temperature, where the heat transfer coefficient dropped rapidly at increasing vapor quality. A special rig was also built in order to observe two-phase flow patterns. A horizontal quartz glass tube with internal diameter of $0.98 \mathrm{~mm}$ coated by transparent resistive coating of indium tin oxide was used to perform the tests. Two-phase flow patterns were recorded mainly at a temperature of $20^{\circ} \mathrm{C}$, and mass flux ranging from 100 to $580 \mathrm{~kg} /\left(\mathrm{m}^{2} \mathrm{~s}\right)$. The observation showed a dominance of intermittent (slug) flow at low vapor qualities, and wavy annular flow with entrainment at higher vapor qualities. At high mass flux, the annular/entrainment flow pattern was described as dispersed. Stratified flow was not observed in the tests with heat load. The nucleate (pool) boiling correlation of Gorenflo (1993) gave the best fit to the experimental data; values $8 \%$ above the test data on average (using a reference coefficient of $\left.4170 \mathrm{~W} /\left(\mathrm{m}^{2}{ }^{\circ} \mathrm{C}\right)\right)$.

Palm (2001) also presented a good review on heat transfer in microchannels. He stated that for two-phase flow, very little information was available for microchannels. Especially, the size range below $1 \mathrm{~mm}$ had been investigated by only a few researchers, most of them concerning to evaporation. Related to $\mathrm{CO}_{2}$ evaporation on microchannels, Palm (2001) mentioned only the work performed by Zhao et al. (2000), commented earlier in this work. He concluded from this review that flow boiling was governed mainly by nucleate boiling mechanisms in the diameter range below about $4 \mathrm{~mm}$. A pool boiling correlation such as Coopers' gave reasonable but conservative values for heat transfer coefficient as long as the critical heat flux was not reached. Like Pettersen (2001), he also concluded that there were still many open questions to be answered before reliable design tools were available in the form of correlating equations for heat transfer and pressure drop and suggested that more research was needed in this field.

As mentioned before, among the few works in this area, experimental results performed by Hihara and Tanaka (2000) and Koyama et al. (2001) are found, who utilized a single stainless steel tube in order to obtain the heat transfer coefficient. However, they did not perform the flow visualization, which is an important characteristic when dealing with phase change. As mentioned by Thome (2001), the best approaches for modeling two-phase heat transfer and two-phase pressure drops are based on two-phase flow pattern analysis.

Zhao et al. (2000) and Ohadi et al. (2000) used a test rig containing several parallel microchannels, which introduce an additional variable to the problem: the flow distribution through the microchannels. Like Hihara and Tanaka (2000), and Koyama et al. (2001), they also did not perform the flow visualization.

Only Pettersen (2001) presented results for both, heat transfer coefficient and flow visualization. But even Pettersen (2001) did not perform the tests in a same test rig. The heat transfer coefficients were measured in a test rig containing several microchannels and the flow visualization were performed in a different test rig using a glass tube in order to permit the visual access to the flow. At these conditions, the heat transfer data and the flow visualization results could not be exactly interrelated.

In this work, a test rig with a single microchannel was used in order to measure the heat transfer coefficient and to visualize the flow patterns in the same experimental setup.

\section{Nomenclature}

$\mathrm{A}=\mathrm{area}, \mathrm{m}^{2}$

$\mathrm{G}=$ mass flux (mass velocity, $\mathrm{kg} /\left(\mathrm{m}^{2} \mathrm{~s}\right.$ )

$\mathrm{G}_{\mathrm{wavy}}=$ stratified wavy-intermittent/annular mass flux transition, $\mathrm{kg} /\left(\mathrm{m}^{2} \mathrm{~s}\right)$

$\mathrm{G}_{\text {strat }}=$ stratified-stratified wavy mass flux transition, $\mathrm{kg} /\left(\mathrm{m}^{2} \mathrm{~s}\right)$

$\mathrm{H}=$ heat transfer coefficient, $W /\left(m^{2}{ }^{\circ} \mathrm{C}\right)$

$\mathrm{h}_{\mathrm{o}}=$ Gorenflo reference heat transfer coefficient, $4170 \mathrm{~W} /\left(\mathrm{m}^{2}{ }^{\circ} \mathrm{C}\right)$

$\mathrm{h}^{*}=$ heat transfer coefficient inside channel $3,15 \mathrm{~kW} /\left(\mathrm{m}^{2}{ }^{\circ} \mathrm{C}\right)$

$\mathrm{k}=$ thermal conductivity, $W /\left(m{ }^{\circ} \mathrm{C}\right)$

$\mathrm{L}=$ length, $m$

$\mathrm{m}=$ mass, $\mathrm{kg}$

$\dot{\mathrm{m}}=$ mass flow rate, $\mathrm{kg} / \mathrm{s}$

$\mathrm{P}=$ perimeter,$m$

$\mathrm{Q}=$ heat flux, $\mathrm{W} / \mathrm{m}^{2}$

$\dot{\mathrm{Q}}=$ heat load (power), $W$

$\mathrm{q}_{\mathrm{r}}=$ radial heat flux, $\mathrm{W} / \mathrm{m}^{2}$

$\mathrm{r}_{\mathrm{e}}=$ external radius of channel $3, \mathrm{~m}$

$\mathrm{r}_{\mathrm{i}}=$ internal radius of channel $3, \mathrm{~m}$

$\mathrm{T}=$ temperature, ${ }^{\circ} \mathrm{C}$

$\mathrm{R}=$ heater resistance, $\Omega$

$\mathrm{V}=$ voltage, $V$

$\mathrm{x}=$ vapor quality

$\mathrm{XIA}=$ intermittent-annular transition vapor quality

Greek

$\Delta \mathrm{t}$ time interval, $\mathrm{s}$

$\Delta \mathrm{T}=\mathrm{T}_{\mathrm{w}}-\mathrm{T}_{\text {sat }}$ temperature difference at the microchannel, ${ }^{\circ} \mathrm{C}$

$\theta_{\mathrm{b}} \quad$ fitting base temperature, ${ }^{\circ} \mathrm{C}$

$\sigma$ standard deviation

\section{Subscripts}

amb ambient

ch channel

cs cross section

e external

fit fitting

I internal

sat saturation

w wall

w3 wall of channel 3

1,2 , and 3 channels 1,2 and 3, respectively, for areas

1 to 10 thermocouple location for temperature measurements

\section{Experimental Method}

\section{Overview}

A once-through, open-loop, $\mathrm{CO} 2$ delivery system was designed by Aldana (2000), and modified in this work, to allow control of the $\mathrm{CO} 2$ thermodynamic state entering the test section inlet. The test loop is shown in Fig. 1. 


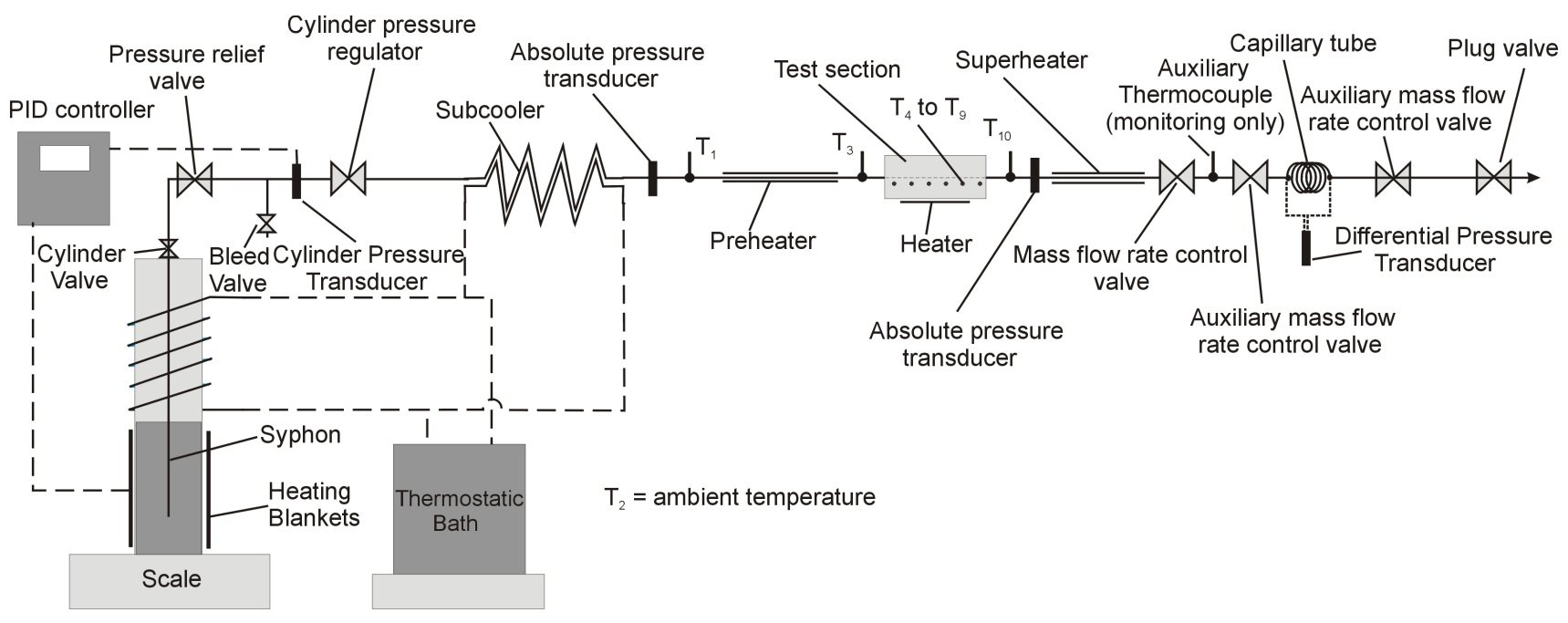

Figure 1. Carbon dioxide open loop system.

The $\mathrm{CO}_{2}$ source was a $9.1 \mathrm{~kg}$ liquid- $\mathrm{CO}_{2}$ cylinder with a central riser tube that allowed liquid to be syphoned from the cylinder bottom. Electric heating blankets were used to increase the $\mathrm{CO}_{2}$ cylinder temperature and pressure to a desired value. Once a target pressure was reached, the regulator was opened and $\mathrm{CO}_{2}$ flowed down a chilled inlet section, named subcooler, which ensured subcooled liquid entered the preheater. The preheater was a copper tube wrapped by an electric heater and was used to set a desired vapor quality at the inlet of the test section. Mass flow rate was calculated from the decrease in source-cylinder mass over time. The pressure difference in the $\mathrm{CO}_{2}$ superheated vapor flow through a capillary tube installed at the end of the test loop was used for monitoring the mass flow rate. Throttle valves in the exhaust line were used to adjust the desired mass flow rate. Transducer data allowed monitoring of flow conditions, and were imputed into a PCbased Data Acquisition System (DAS). Thermocouple and pressure readings were hardwired into a National Instruments ${ }^{T M}$ data acquisition board and routed directly to a personal computer. Data interpretation and manipulation was performed using the software package LabVIEW 5.0 by National Instruments ${ }^{\mathrm{TM}}$. The following hardware was used to receive and interpret the input data: data acquisition device, PCI-MIO-16XE-10 (up to $100 \mathrm{kHz}$ data acquisition capability); SCXI Chassis, SCXI-1000; SCXI module, SCXI-1100; and terminal block, SCXI-1300. The sampling frequency used was $1 \mathrm{kHz}$ for each channel, however each point showed in Fig. 3 represents an average of 500 data. Specific aspects of the test loop are described as follows.

\section{Control of $\mathrm{CO}_{2}$ Cylinder Pressure}

A pressure relief valve, bleed valve, and pressure transducer were placed in-line before the pressure regulator. The in-line relief valve (designed to begin opening at $10.32 \mathrm{MPa}$ ) ensured emergency removal of over-pressurized $\mathrm{CO}_{2}$ far below the cylinder burst pressure of $41.3 \mathrm{MPa}$. The bleed valve allowed removal of the inline pressure between the outlet and the closed cylinder valve. The pressure transducer allowed pressure measurements of the source cylinder. Two $15.5 \mathrm{~kW} / \mathrm{m}^{2}$ heating blankets were clamped to the cylinder, and used to control the pressure inside the cylinder. A copper tube heat exchanger connected to a $50 \%$ water-50\% ethylene glycol temperature bath was wrapped around the $\mathrm{CO}_{2}$ cylinder in order to improve the pressure control. The cylinder was then insulated with foil-faced polyethylene air pillow wrap. A control box was used to regulate and monitor the cylinder conditions with a
PID (Proportional Integral Differential) feedback loop, which also provided power to the heating blankets. A variable transformer allowed variable control of the blanket heat density $\left(0-15.5 \mathrm{~kW} / \mathrm{m}^{2}\right)$.

\section{Control of the $\mathrm{CO}_{2}$ Test Section Inlet Vapor Quality}

Before reaching the test section inlet the $\mathrm{CO}_{2}$ flowed through a subcooler in order to permit that subcooled liquid entered the preheater. The subcooler was a copper tube counterflow heat exchanger using a $50 \%$ water-50\% ethylene glycol mixture, cooled to $0^{\circ} \mathrm{C}$ in a temperature bath, as a heat sink. The preheater, a copper tube heat exchanger wounded by an electric heater, was used to allow that saturated $\mathrm{CO}_{2}$ entered the test section inlet at a desired vapor quality. A variable transformer was used to adjust the voltage supplied to the electric heater and a digital voltmeter was used to measure the voltage. The supplied electric power was calculated by knowing the resistance of the heater. A polyethylene foam tube was utilized to insulate the preheater in order to minimize the heat transfer to the ambient. The inlet and outlet temperatures of the $\mathrm{CO}_{2}$ flow in the preheater were measured by two $1.5875-\mathrm{mm}$ diameter type-K thermocouples installed inside the flow through fitting, and the energy balance was applied to determine the inlet vapor quality at the test section. A pressure transducer was used to measure the absolute pressure at the preheater inlet, which was needed to determine the inlet state of the $\mathrm{CO}_{2}$ flow. Three 0.254-mm diameter type- $K$ thermocouples were installed on the insulation surface and the temperatures measured were used to estimate the heat transfer interactions with the ambient, resulting values lower than $1 \%$ compared to the supplied electric power.

\section{Control of the Mass Flow Rate}

Mass flow rates were determined by using a 1-gram resolution scale. The cylinder, including the heating blankets, insulation, and tubing, was placed on the scale and the total weight measured. As $\mathrm{CO}_{2}$ exited the cylinder, the reduction in mass was measured over time. A needle valve installed after the superheater was used to throttle the flow, controlling the mass flow rate. Two other valves were installed after the needle valve to improve the mass flow rate control. Another copper-tube electric heater, named superheater, was installed with the objective of superheating the $\mathrm{CO}_{2}$ before entering the needle control valve in order to avoid temperature reduction in the flow through the needle valve; otherwise it would be difficult to get a good control on the mass flow rate. In order to 
have an instantaneous control on the mass flow rate, it was installed a capillary tube after the control valves. The pressure drop of the $\mathrm{CO}_{2}$ superheated flow through the capillary tube was used as a signal for monitoring the stability of the mass flow rate.

\section{Test Section}

Figure 2 shows a layout of the test section, which consisted of a rectangular microchannel milled into an aluminum substrate. Aluminum was chosen as the substrate material to model conditions within a compact heat exchanger. The section consisted of a lower frame, including the microchannel, piping, and instrumentation; a glass window that allowed for flow visualization; and an upper frame, which clamped down over the window onto the lower frame and provided a pressure seal. The $0.794-\mathrm{mm} \times 0.6858-\mathrm{mm} \times 50.8$ $\mathrm{mm}$ microchannel had 1.6-mm diameter inlet and outlet ports bored at right angles into the substrate, allowing an o-ring groove to be milled around both ports and encircle the channel. The aluminum substrate provided three of the four microchannel walls. The fourth wall was a $6.35-\mathrm{mm}$ rectangular glass window that cradled inside the lower frame. The rectangular upper frame bolted to the lower frame with 20 lockdown screws, compressing the glass onto an oring and providing the pressure seal. The glass window was protected from the upper frame by gasket material. The upper frame provided a $10.16-\mathrm{mm} \times 63.5-\mathrm{mm}$ viewing area of the entire microchannel.

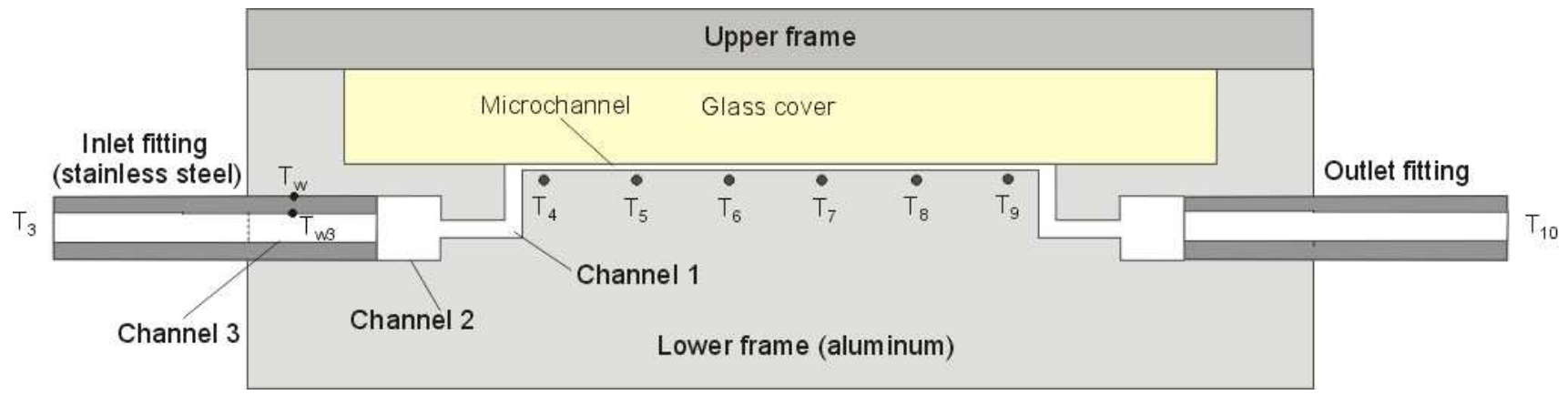

Figure 2. Microchannel test section.

Two 1.5875-mm diameter type-K thermocouples were installed inside the flow through fittings at the inlet and outlet of the test section in order to measure the temperature of the $\mathrm{CO}_{2}$, and a pressure transducer was installed at the exit of the test section. Six type-K thermocouples with $0.254-\mathrm{mm}$ diameter stainless steel sheath and ungrounded junction were installed at the bottom of the microchannel through holes drilled into the lower frame. A 50.8- $\mathrm{mm}$ x $50.8-\mathrm{mm}$ square ultra-thin heating blanket $\left(15.5 \mathrm{~kW} / \mathrm{m}^{2}\right)$ was attached to the back of the lower frame, located $18 \mathrm{~mm}$ from the microchannel and the thermocouples, to provide a heat flux to the $\mathrm{CO}_{2}$ in the microchannel. The entire test section was insulated using polyethylene foam to minimize heat transfer to the ambient. Three 0.254-mm diameter type- $\mathrm{K}$ thermocouples were installed on the insulation surface and the temperatures measured were used to estimate the heat transfer interactions with the ambient.

\section{Running a Test}

The first step in running the $\mathrm{CO}_{2}$ experiment was to obtain the desired pressure within the source cylinder. After adjusting the desired pressure level in the test and setting a heating value to the heating blankets, the cylinder valve was fully opened with the pressure regulator fully closed. Once the cylinder target pressure was achieved, the pressure regulator was fully opened, and $\mathrm{CO}_{2}$ flowed through the subcooler and the preheater before reaching the test section inlet. $\mathrm{CO}_{2}$ entered the test section at the left side through a stainless steel fitting, flowed through a $2.4-\mathrm{mm}$ diameter $5 \mathrm{~mm}$ channel length (channel 3, still inside the fitting), and then flowed through a 6.4-mm diameter 8.8-mm channel length (channel 2), and a 1.6-mm diameter 17.0-mm channel length (channel 1) before reaching the microchannel. Then the $\mathrm{CO}_{2}$ flowed within the 50.8$\mathrm{mm}$ microchannel length across the test section front towards the outlet port. The outlet-piping configuration was similar to the inlet configuration. After flowing through the microchannel, the $\mathrm{CO}_{2}$ flowed through the superheater, the mass flow rate control valves, and the capillary tube, towards the line exit, and was exhausted to the ambient. All data were recorded during five minutes after the steady state regime was reached. A PC-based Data Acquisition System (DAS) was used to process transducers data collected from the test loop. During the time of data recording several photographs of the flow were taken using a digital camera.

\section{Data reduction and Interpretation}

Figure 2 depicts a detail of the test section and is used to describe the methodology developed to calculate the heat transfer coefficient from the experimental data. The heat supplied by the electric heater to the flow was supposed to be distributed as:

$$
\begin{aligned}
& \dot{\mathrm{Q}}=\mathrm{h}\left(\mathrm{A}_{\mathrm{ch}}+2 \mathrm{~A}_{1}+2 \mathrm{~A}_{2}\right)\left(\mathrm{T}_{\mathrm{w}}-\mathrm{T}_{\mathrm{sat}}\right)+ \\
& +2 \mathrm{~h} \mathrm{~A}_{3}\left(\mathrm{~T}_{\mathrm{w} 3}-\mathrm{T}_{\mathrm{sat}}\right)+\dot{\mathrm{Q}}_{\mathrm{amb}}+2 \dot{\mathrm{Q}}_{\mathrm{fit}}
\end{aligned}
$$

In this model, it was assumed that the heat transfer coefficient was uniform at the four channels: microchannel and channels 1,2 and 3, which have the heat transfer areas equal to $A_{c h}=110 \mathrm{~mm}^{2}$, $\mathrm{A}_{1}=85,5 \mathrm{~mm}^{2}, \mathrm{~A}_{2}=177 \mathrm{~mm}^{2}$, and $\mathrm{A}_{3}=37,7 \mathrm{~mm}^{2}$, respectively. The channel heat transfer area was assumed to be formed by the three aluminum sides in contact with the flow; the fourth glass side was considered to be insulated. The saturation temperature was assumed to have three values: the temperature at the test section inlet, $\mathrm{T}_{3}$; the temperature at the test section outlet, $\mathrm{T}_{10}$; and the average temperature of $T_{3}$ and $T_{10}$, named here by $T_{w}$. For each of these saturation temperatures it was calculated a heat transfer coefficient. The results of this calculation procedure can be seen in Fig. 5, which shows three values for the heat transfer coefficient, $h$, for each vapor quality.

The wall temperature of the microchannel, $T_{w}$, was calculated as the average of the temperatures $\mathrm{T}_{4}$ to $\mathrm{T}_{9}$. A typical standard 
deviation for $\mathrm{T}_{\mathrm{w}}$ was about $0.025^{\circ} \mathrm{C}$. Fig. 3 shows a typical result of the signal obtained for $\mathrm{T}_{4}$ to $\mathrm{T}_{9}$.

This uniform value for $T_{w}$ along the microchannel suggested the assumption of a constant wall temperature for all channels made in the aluminum substrate. Instead, owing to the lower thermal conductivity of the stainless steel fitting, another wall temperature, $\mathrm{T}_{\mathrm{w} 3}$, was estimated for channel 3. Based on the conduction resistance of the fitting, the following equation was used to estimate $\mathrm{T}_{\mathrm{w} 3}$,

$$
\mathrm{T}_{\mathrm{w} 3}=\mathrm{T}_{\mathrm{w}}-\mathrm{q}_{\mathrm{r}}\left[\ln \left(\mathrm{r}_{\mathrm{e}} / \mathrm{r}_{\mathrm{i}}\right) /(2 \pi \mathrm{kL})\right]
$$

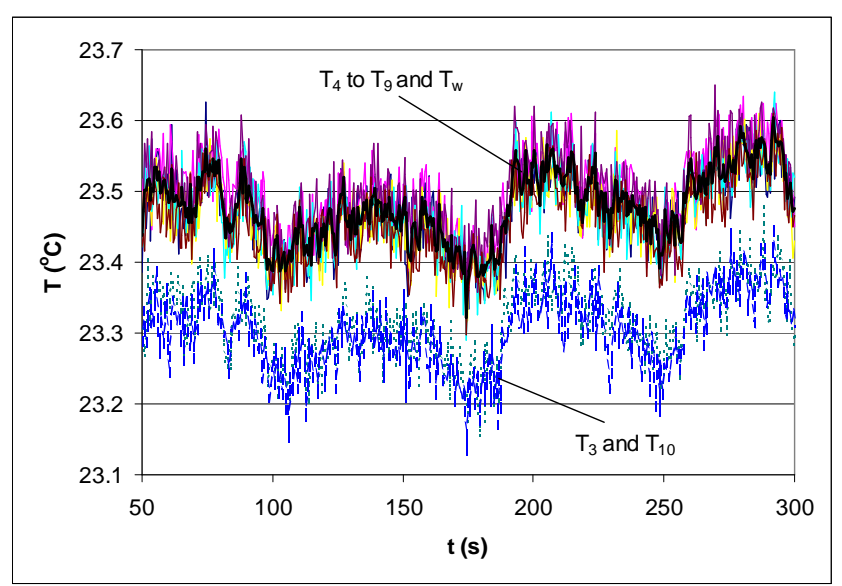

Figure 3. Signals obtained for T3 to T10 from a typical test.

where,

$$
\mathrm{q}_{\mathrm{r}}=\left(\mathrm{T}_{\mathrm{W}}-\mathrm{T}_{\mathrm{sat}}\right) /\left[1 /\left(2 \pi \mathrm{r}_{\mathrm{i}} \mathrm{Lh}^{*}\right)+\ln \left(\mathrm{r}_{\mathrm{e}} / \mathrm{r}_{\mathrm{i}}\right) /(2 \pi \mathrm{kL})\right]
$$

The fittings were considered as two infinite fins insulated externally and connected into the aluminum substrate. A typical value of $15 \mathrm{~kW} /\left(\mathrm{m}^{2 \circ} \mathrm{C}\right)$ for the heat transfer coefficient during the $\mathrm{CO}_{2}$ evaporation inside the fitting channel, $\mathrm{h}^{*}$, was used to estimate the heat loss through the fittings, $\dot{\mathrm{Q}}_{\mathrm{fit}}$. The well-known equation for infinite fin was used,

$$
\dot{\mathrm{Q}}_{\mathrm{fit}}=\left(\mathrm{h}^{*} \mathrm{PkA}_{\mathrm{cs}}\right)^{1 / 2} \theta_{\mathrm{b}}
$$

where,

$$
\begin{gathered}
\theta_{\mathrm{b}}=\left(\mathrm{T}_{\mathrm{w}}+\mathrm{T}_{\mathrm{w} 3}\right) / 2-\mathrm{T}_{\mathrm{sat}} \\
\mathrm{P}=2 \pi \mathrm{r}_{\mathrm{i}} \\
\mathrm{A}_{\mathrm{cs}}=\pi\left(\mathrm{r}_{\mathrm{e}}^{2}-\mathrm{r}_{\mathrm{i}}^{2}\right)
\end{gathered}
$$

The results showed that $\dot{\mathrm{Q}}_{\mathrm{fit}}$ was 5\% of $\dot{\mathrm{Q}}$ in average. The heat transfer to the ambient, $\dot{\mathrm{Q}}_{\mathrm{amb}}$, was estimated by measuring surface temperatures of the insulation and ambient temperature and showed to be negligible compared to other heat transfer values.

\section{Instrumentation and Uncertainty}

A PC-based Data Acquisition System (DAS) was used to process thermocouples and pressure transducers data collected from the test loop. A digital multimeter was used to measure voltages and electric resistances. The type- $\mathrm{K}$ thermocouples were calibrated using a $0.1^{\circ} \mathrm{C}$-resolution mercury-in-glass thermometer and a $0^{\circ} \mathrm{C}$-ice bath in the temperature range from $0^{\circ} \mathrm{C}$ to $30^{\circ} \mathrm{C}$ (a reference thermocouple was placed in a Dewar flask containing finely ground ice chips and water, creating a two-phase ice bath). In this temperature range a linear regression of the data showed a $2-\sigma$ uncertainty of $\pm 0.2^{\circ} \mathrm{C}$ for the voltage-temperature curve fitting. Otherwise, for the temperature range from $19^{\circ} \mathrm{C}$ to $25^{\circ} \mathrm{C}$, which was the temperature range used to calculate the heat transfer coefficients, another voltage-temperature curve fitting was performed, leading to a 2- $\sigma$ uncertainty of $\pm 0.05^{\circ} \mathrm{C}$. This value was used to estimate the uncertainty of the difference between the microchannel wall and saturation temperatures, $\Delta \mathrm{T}=\mathrm{T}_{\mathrm{w}}-\mathrm{T}_{\mathrm{sat}}$, which is the most expressive contribution in the estimation of the heat transfer coefficient uncertainty. Another influencing factor on this uncertainty is the fluctuation of the temperature signals during the tests. As can be seen in Fig. 4, a typical standard deviation of the $\Delta \mathrm{T}$ signals was about $0.025^{\circ} \mathrm{C}$ for the same test showed in Fig. 3. Combining the uncertainty of the thermocouple calibration $\left( \pm 0.07^{\circ} \mathrm{C}\right.$, which includes the uncertainty of the mercury-in-glass thermometer, $\pm 0.05^{\circ} \mathrm{C}$, and the uncertainty of the voltage-temperature curve fitting, $\pm 0.05^{\circ} \mathrm{C}$ ) with the $2-\sigma$ fluctuation of the $\Delta \mathrm{T}$ signal on the RMS base, one can estimate the uncertainty of $\mathrm{T}_{\mathrm{w}}-\mathrm{T}_{\text {sat }}$ in $\pm 0.1^{\circ} \mathrm{C}$.

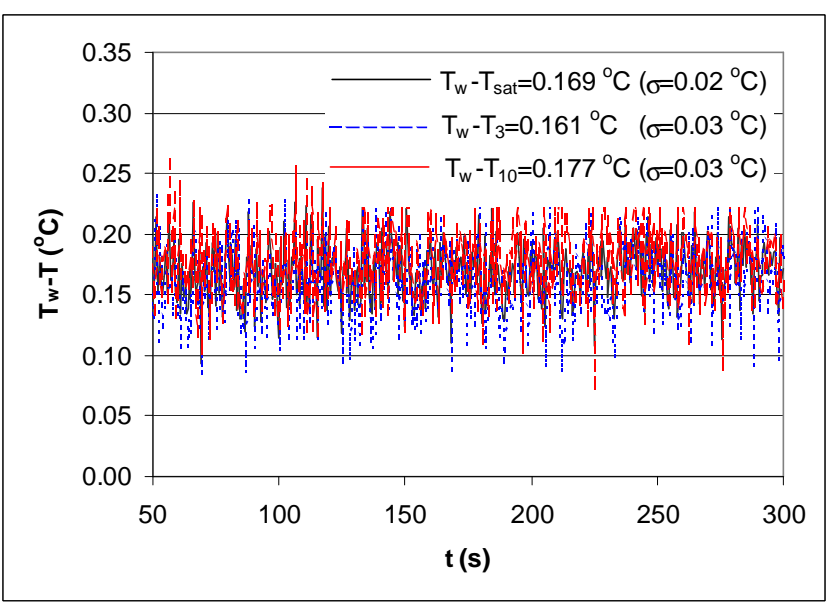

Figure 4. $\Delta \mathrm{T}$ signals considering three values for the saturation temperature.

The manufacture-stated absolute pressure transducer and differential pressure transducer accuracies were $\pm 0.13 \%$ full scale $( \pm 10 \mathrm{kPa})$, and $\pm 0.15 \%$ of the full scale $( \pm 0.26 \mathrm{kPa})$, respectively. The uncertainties of all measured variables are presented in Table 1.

The uncertainties of reduced data were determined by propagating the measurement uncertainties using the methodology proposed by Moffat (1988). The results are shown in Table 2.

\section{Results and Discussion}

A total of 105 experimental tests were conducted, including subcooled liquid flow, saturated flow and superheated flow. Data from 67 tests (including 6 tests in which dryout was observed) were used to estimate the heat transfer coefficient, and visualization of the flow during the $\mathrm{CO}_{2}$ evaporation was performed in 28 tests. All tests 
were performed for one heating value of $1.28 \mathrm{~W}$ at the bottom of the test section, considering mass flux in the range of 58 to $235 \mathrm{~kg} /\left(\mathrm{m}^{2} \mathrm{~s}\right)$ and inlet vapor qualities from 0.005 to 0.88 . The heat flux at the bottom of the microchannel was estimated in $1800 \pm 5 \% \mathrm{~W} / \mathrm{m}^{2}(2-\sigma$ dispersion), and the saturation temperature was estimated in $23.3 \pm 0.3^{\circ} \mathrm{C}$ (2- $\sigma$ dispersion) for all saturated flow tests.

Table 1. Uncertainty of the measured variables.

\begin{tabular}{|l|l|}
\hline \multicolumn{1}{|c|}{ Variable } & \multicolumn{1}{c|}{ Uncertainty } \\
\hline Voltage $(\mathrm{V})$ & $\pm 1 \%$ of value \\
\hline Electric resistance $(\mathrm{R})$ & $\pm 2 \%$ of value \\
\hline Mass $(\mathrm{m})$ & $\pm 5 \%$ of value \\
\hline Time interval $(\Delta \mathrm{t})$ & $\pm 1 \%$ of value \\
\hline Channel dimensions & $\pm 0.01 \mathrm{~mm}$ \\
\hline Other dimensions & $\pm 0.2 \mathrm{~mm}$ \\
\hline Enthalpy & $\pm 5 \%$ of value \\
\hline $\mathrm{T}_{\mathrm{w}}-\mathrm{T}_{\text {sat }}$ & $\pm 0.1{ }^{\circ} \mathrm{C}$ \\
\hline Absolute pressure & $\pm 0.13 \%$ \\
\hline Differential pressure & $\pm 0.15 \%$ \\
\hline Other temperatures & $\pm 0.2^{\circ} \mathrm{C}$ \\
\hline
\end{tabular}

\section{$T_{\text {sat }}=23.3^{\circ} \mathrm{C} \quad q=1800 \mathrm{~W} / \mathrm{m}^{2}$}

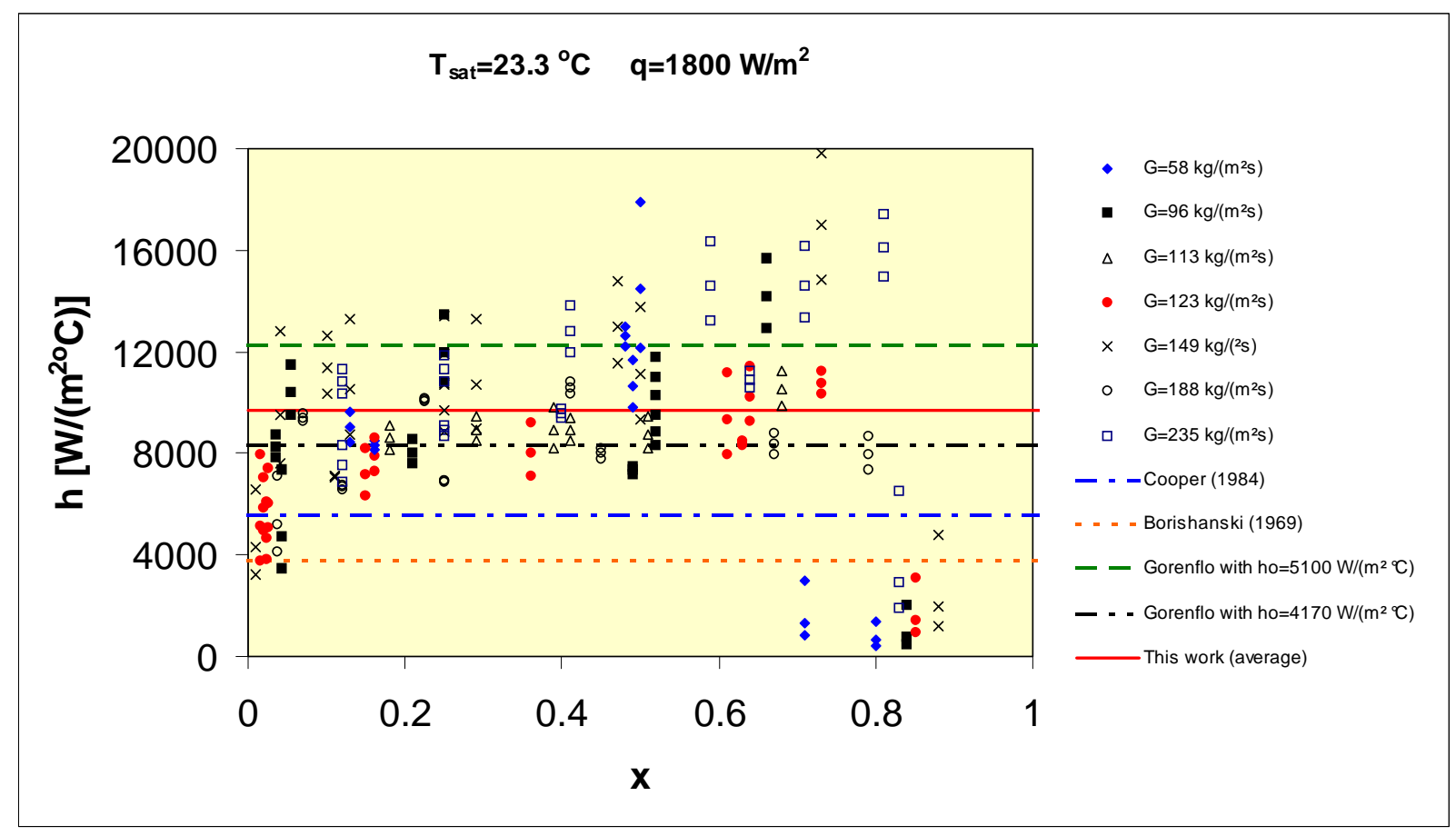

Figure 5. Heat transfer coefficient for all 67 tests.

These correlations and the correlation proposed by Bandarra Filho (1997), cited in Bandarra Filho (2002), were used in order to reproduce the data also quantitatively, but failed to fit the experimental data, under-predicting all the results. Two important facts could be used to explain these discrepancies: the correlations have not been developed for microchannel flows, and the
Table 2. Uncertainty of the reduced data.

\begin{tabular}{|l|l|}
\hline \multicolumn{1}{|c|}{ Variable } & \multicolumn{1}{c|}{ Uncertainty } \\
\hline$\dot{\mathrm{Q}}=\mathrm{V}^{2} / \mathrm{R}$ & $\pm 3 \%$ of value \\
\hline$\dot{\mathrm{m}}=\mathrm{m} / \Delta \mathrm{t}$ & $\pm 5 \%$ of value \\
\hline $\mathrm{A}_{\mathrm{ch}}$ & $\pm 1 \%$ of value \\
\hline other areas & $\pm 10 \%$ of value \\
\hline $\mathrm{G}=\dot{\mathrm{m}} / \mathrm{A}_{\mathrm{ch}}$ & $\pm 5 \%$ of value \\
\hline $\mathrm{x}$ & $\pm 10 \%$ of value \\
\hline $\mathrm{h}$ & $\pm 40 \%$ of value \\
\hline
\end{tabular}

\section{Heat Transfer Coefficient}

Results for heat transfer coefficients are presented in Fig. 5. Despites of the relatively high data scattering, some characteristics of the overall behavior of the heat transfer coefficient may be taken from this figure. It can be noted small heat transfer coefficients for mass fraction lower than about 0.1, which are usual results for the nucleate boiling region. For intermediary mass fractions, ranging from about 0.1 to 0.5 , the heat transfer coefficient shows weak increasing tendency. For mass fraction ranging from 0.5 to 0.85 , one can speculate that the heat transfer coefficient slightly increases. Finally, for mass fractions around 0.85 there is a sudden reduction in the heat transfer coefficient, which characterizes the dryout of the flow. This overall qualitative behavior is in agreement with the results produced by the heat transfer correlations proposed by Sha (1982) and Kandlikar (1990), as shown in Bandarra Filho (2002). investigators have not used carbon dioxide flow data to obtain the correlations. In addition to the geometric difference, the working fluid plays an important role in the case of carbon dioxide flow because of its unusual physical properties, when compared to the other refrigerants. 
For microchannel flow boiling the heat transfer coefficient has been shown experimentally to be similar to nucleate pool boiling heat transfer, Thome (2004). However, based in a new elongated bubble flow heat transfer model developed by Jacobi and Thome (2002), Thome (2004) suggested that the convective boiling model is physically more consistent to predict the heat transfer coefficient in microchannel flows, but concluded that this subject is still in its infancy and much more work remains to be done.

Otherwise, contrary to the suggestion of Thome (2004), Yun et al. (2005) compared their experimental results for convective boiling heat transfer coefficient of carbon dioxide in microchannels to the results produced by nucleate pool boiling correlations, as those proposed by Cooper (1984) and Gorenflo (1993).

By observing the overall behavior of the heat transfer coefficient in Fig. 5, which shows an almost constant heat transfer coefficient, the same procedure of Yun et al. (2005) is used in this work. Therefore, assuming nucleate boiling regime, an average value of $9700 \mathrm{~W} /\left(\mathrm{m}^{2 \circ} \mathrm{C}\right)$ is obtained from all data (except after-dryout data) with a standard deviation of $35 \%$. Comparing to the values given by the correlations of Cooper (1984), Borishanski (1969) and Gorenflo (1993) for nucleate boiling, the Gorenflo (1993) correlation with $\mathrm{h}_{\mathrm{o}}=4170 \mathrm{~W} /\left(\mathrm{m}^{2 \circ} \mathrm{C}\right)$ gave the best fit to these data $(\mathrm{h}=8320$ $\left.\mathrm{W} /\left(\mathrm{m}^{2 \circ} \mathrm{C}\right)\right), 15 \%$ lower than the average experimental result.

\section{Visualization}

Flow visualization results for 28 tests are given in Figs. 6 to 11 . Multiple photographs were taken at different times for each test while measurements were being conducted. In all these figures $\mathrm{CO}_{2}$ flows from the right to the left. Using the flow regimes described by Carey (1992), three types of flow patterns were observed, namely plug, slug, and annular flow. Annular flow was assumed to be the regime when no bubbles were observed in the flow. All patterns were observed for the smaller values of mass flux (up to 149 $\mathrm{kg} /\left(\mathrm{m}^{2} \mathrm{~s}\right)$ ); plug flow was predominant for low qualities (up to about 0.25 ); slug flow was predominant for intermediate qualities (from about 0.25 to 0.50 ), and annular flow was observed for high qualities (above 0.50 ). For mass flux of 188 and $235 \mathrm{~kg} /\left(\mathrm{m}^{2} \mathrm{~s}\right)$, only two flow patterns could be observed: slug and annular flow. Slug flow was predominant for low qualities (up to about 0.25) and annular flow was observed for high qualities. The same tendencies and flow patterns were observed by Pettersen (2001). The visualization results for annular flows were not all much clear. The decision favorable to this flow pattern in some tests was made when no bubble was detected in the flow and some wavelike form appeared on the pictures. Table 4 presents a summary of the flow regimes.

The flow patterns observed in the visualization tests were plotted in Fig. 12 on the flow pattern map developed by Thome and Hajal (2002). This map predicts flow pattern data for seven different refrigerants (not including the $\mathrm{CO}_{2}$ ) covering a wide range of mass velocities (10 to $500 \mathrm{~kg} / \mathrm{m}^{2} \mathrm{~s}$ ), vapor qualities (0.01 to 0.99 ), and saturation pressures (about 0.1 to $0.9 \mathrm{MPa}$ ). An important characteristic of this map is that it is valid for both adiabatic and diabatic (evaporating) flows.

Table 4. Flow regimes for saturated flows.

\begin{tabular}{|c|c|c|c|}
\hline $\mathbf{G}\left(\mathrm{kg} /\left(\mathrm{m}^{2} \mathrm{~s}\right)\right.$ & Test & $\mathbf{x}$ & Flow regime \\
\hline & 1 & 0.13 & Plug \\
\hline & 2 & 0.16 & Plug \\
\hline & 3 & 0.48 & Slug \\
\hline & 10 & 0.06 & Plug \\
\hline & 12 & 0.25 & Plug \\
\hline & 15 & 0.52 & Annular \\
\hline & 16 & 0.66 & Annular \\
\hline \multirow{4}{*}{123} & 24 & 0.02 & Plug \\
\hline & 28 & 0.15 & Plug \\
\hline & 30 & 0.36 & Slug \\
\hline & 31 & 0.61 & Annular \\
\hline \multirow{6}{*}{149} & 36 & 0.01 & Plug \\
\hline & 40 & 0.13 & Plug \\
\hline & 41 & 0.25 & Plug \\
\hline & 43 & 0.29 & Slug \\
\hline & 45 & 0.50 & Slug/annular \\
\hline & 46 & 0.73 & Annular \\
\hline \multirow{5}{*}{188} & 50 & 0.12 & Slug \\
\hline & 52 & 0.25 & Slug \\
\hline & 54 & 0.45 & Slug/annular \\
\hline & 55 & 0.67 & Annular \\
\hline & 56 & 0.79 & Annular \\
\hline \multirow{6}{*}{235} & 58 & 0.12 & Slug \\
\hline & 59 & 0.25 & Slug \\
\hline & 62 & 0.41 & Slug \\
\hline & 63 & 0.59 & Annular \\
\hline & 65 & 0.71 & Annular \\
\hline & 66 & 0.81 & Annular \\
\hline
\end{tabular}

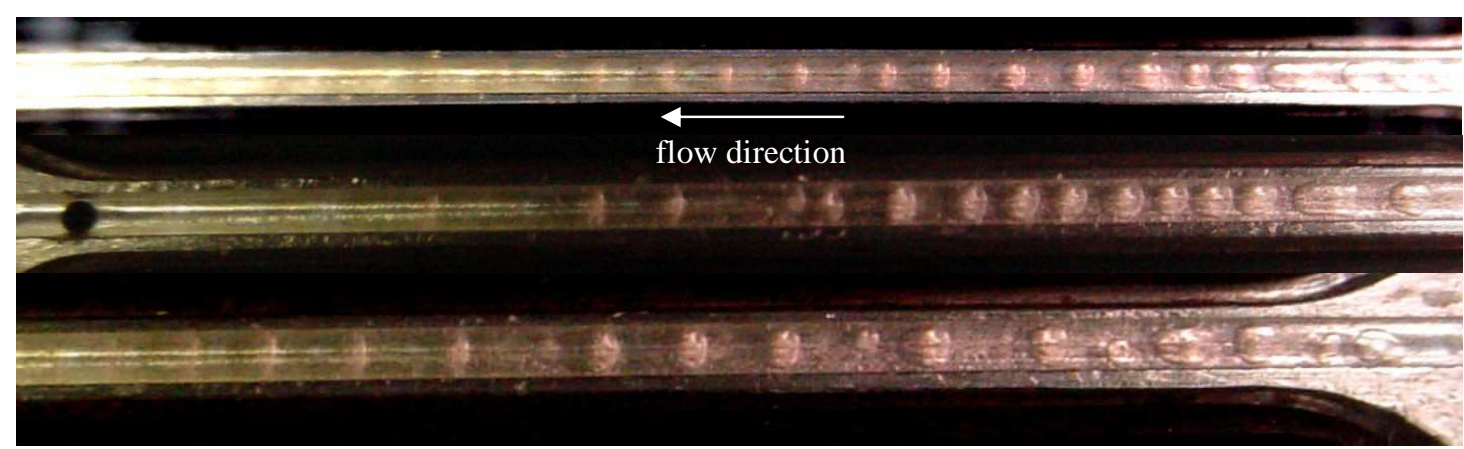

Figure 6(a). Flow pattern in test 1 (plug flow), where $G=58 \mathrm{~kg} /(\mathrm{m} 2 \mathrm{~s})$ and $\mathrm{x}=0.13$. 


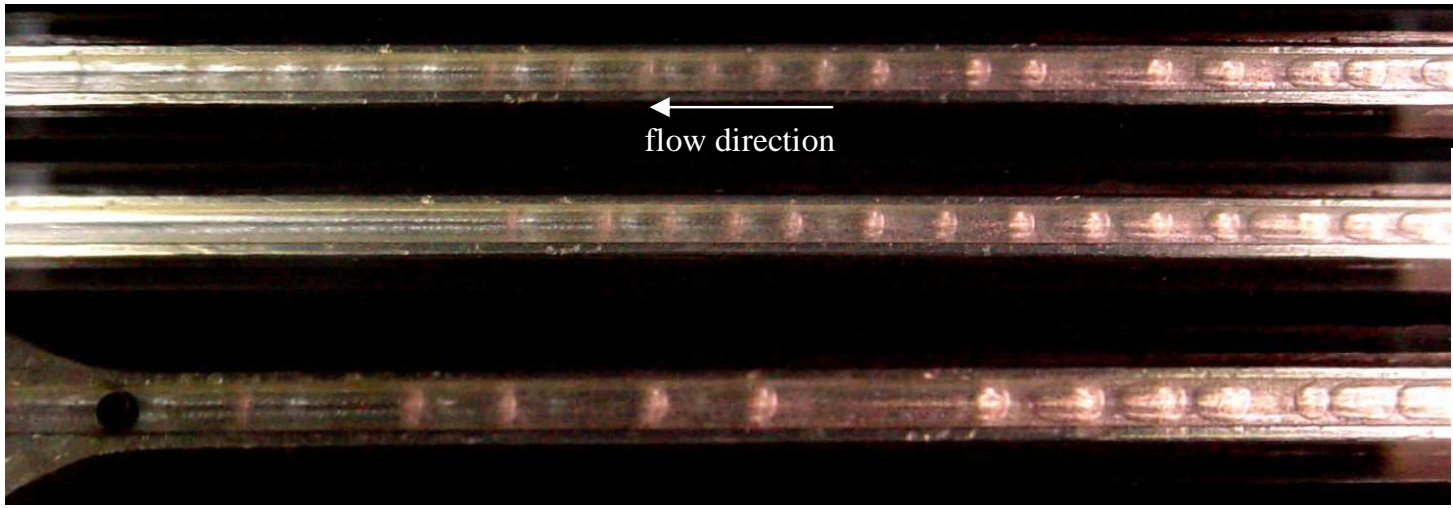

Figure 6(b). Flow pattern in test 2 (plug flow), where $\mathrm{G}=58 \mathrm{~kg} /(\mathrm{m} 2 \mathrm{~s})$ and $\mathrm{x}=0.16$.

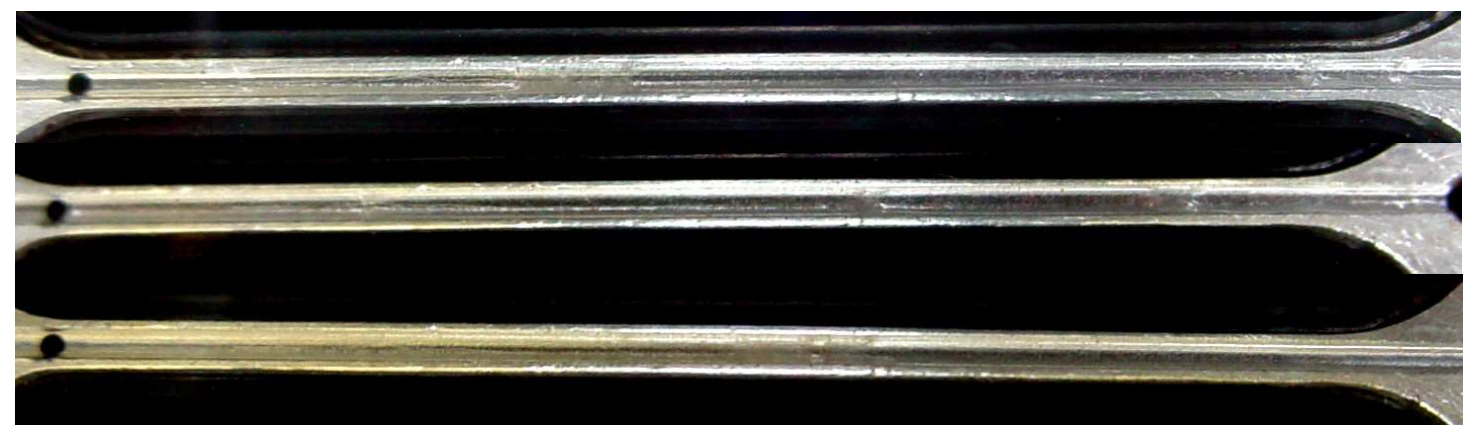

Figure $6(\mathrm{c})$. Flow pattern in test 3 (slug flow), where $\mathrm{G}=58 \mathrm{~kg} /(\mathrm{m} 2 \mathrm{~s}$ ) and $\mathrm{x}=0.48$.

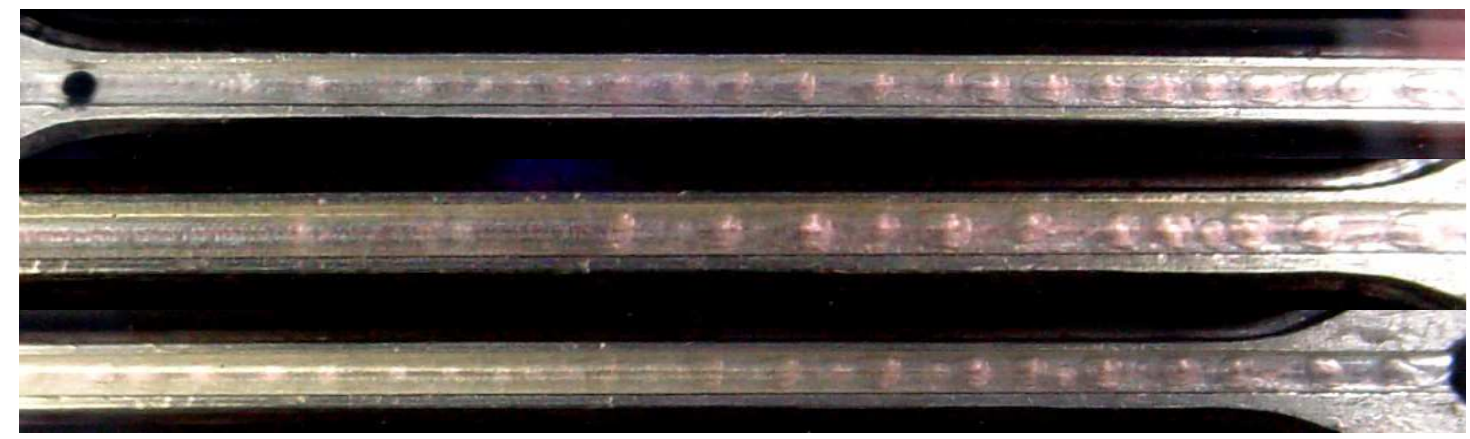

Figure 7(a). Flow pattern in test 10 (plug flow), where $\mathrm{G}=96 \mathrm{~kg} /(\mathrm{m} 2 \mathrm{~s}$ ) and $\mathrm{x}=0.06$.

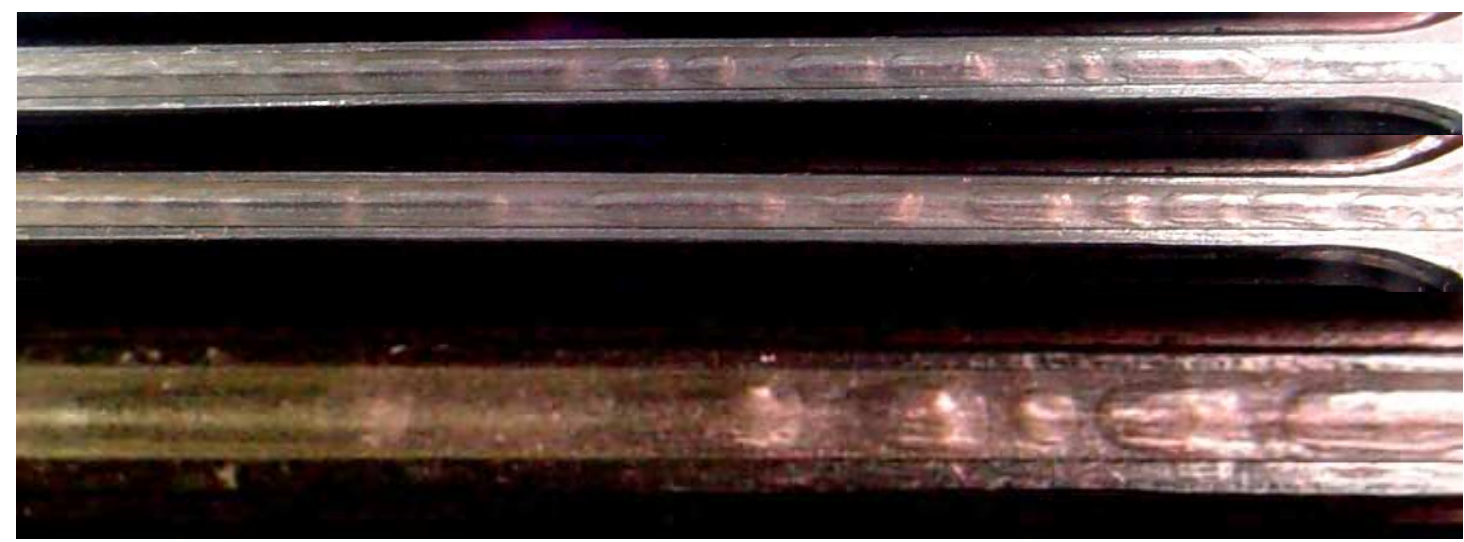

Figure 7(b). Flow pattern in test 12 (plug flow), where $\mathrm{G}=96 \mathrm{~kg} /(\mathrm{m} 2 \mathrm{~s})$ and $\mathrm{x}=0.25$. 


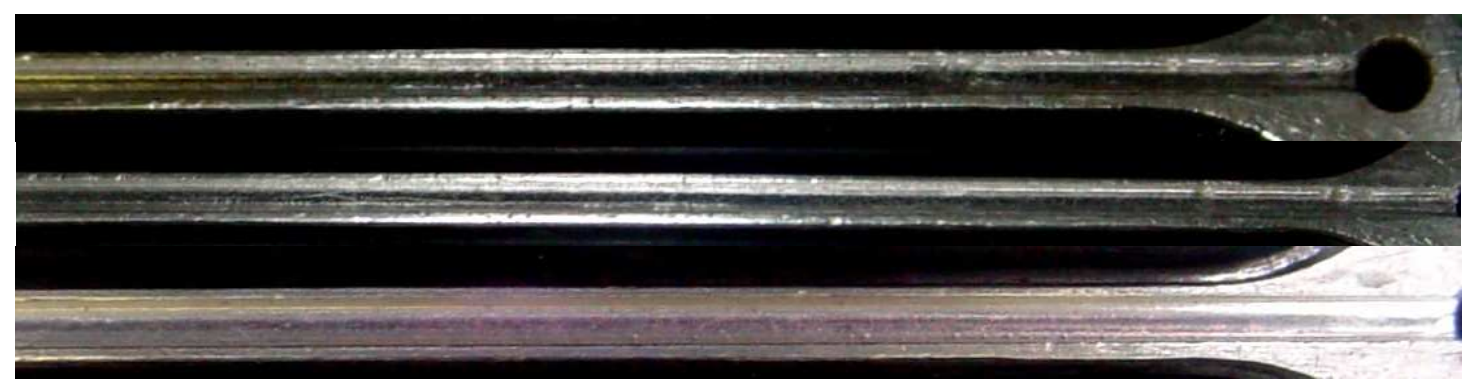

Figure 7(c). Flow pattern in test 15 (annular flow), where $G=96 \mathrm{~kg} /(\mathrm{m} 2 \mathrm{~s})$ and $\mathrm{x}=0.52$.

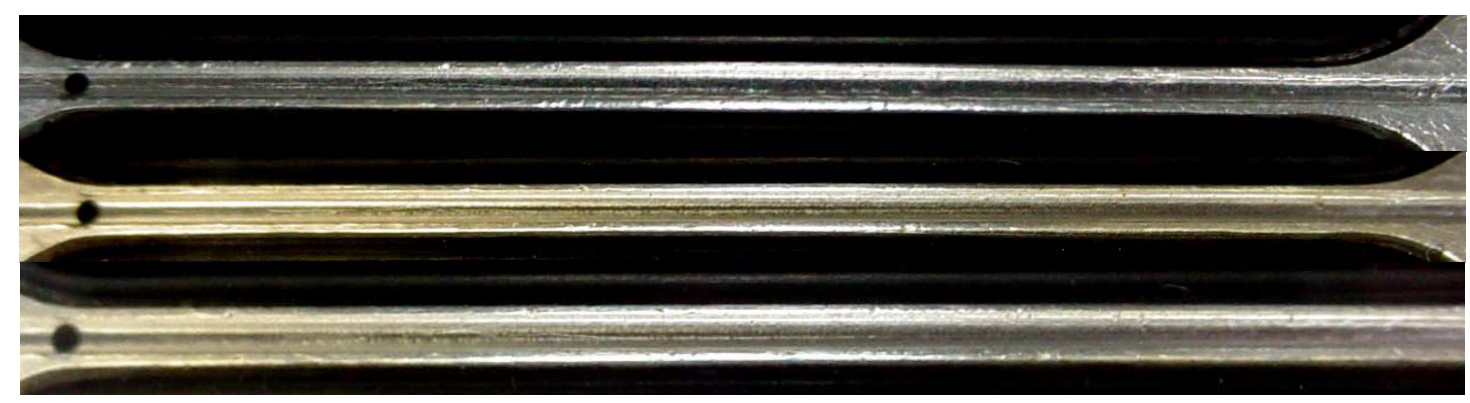

Figure 7(d). Flow pattern in test 16 (annular flow), where $\mathrm{G}=96 \mathrm{~kg} /(\mathrm{m} 2 \mathrm{~s}$ ) and $\mathrm{x}=0.66$.

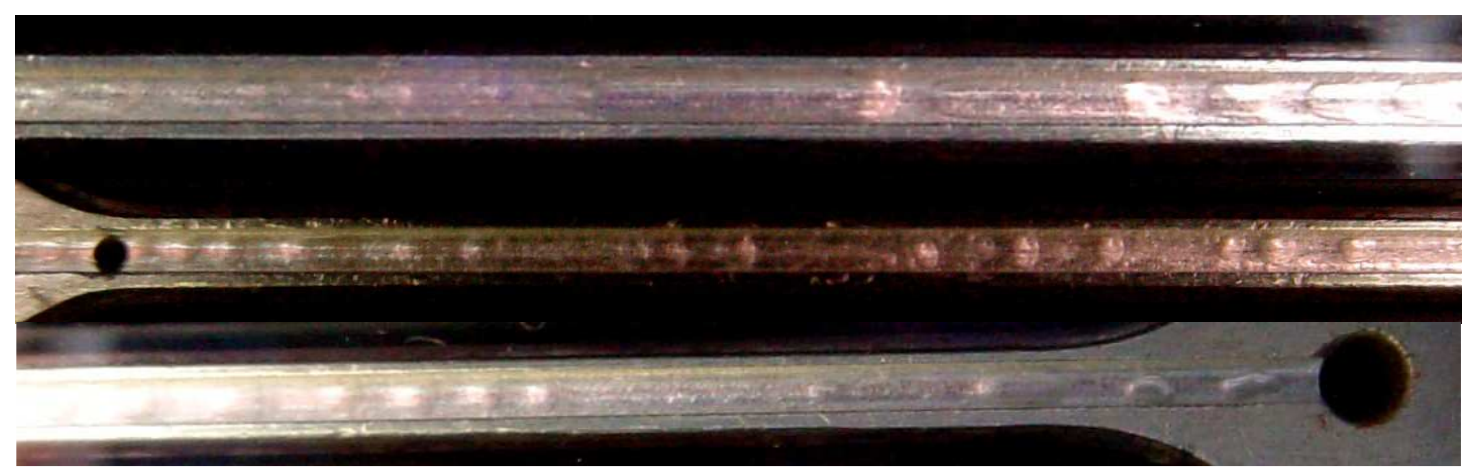

Figure 8(a). Flow pattern in test 24 (plug flow), where $\mathrm{G}=123 \mathrm{~kg} /(\mathrm{m} 2 \mathrm{~s}$ ) and $\mathrm{x}=0.02$.

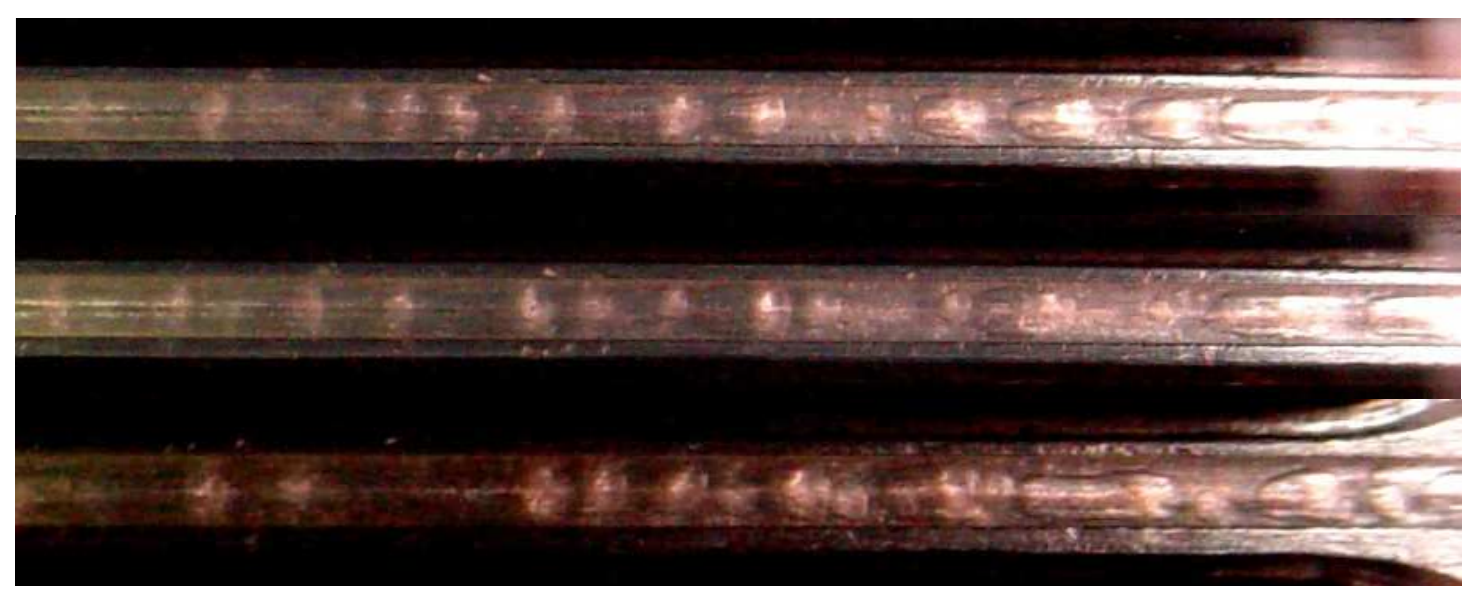

Figure $8(\mathrm{~b})$. Flow pattern in test 28 (plug flow), where $\mathrm{G}=123 \mathrm{~kg} /(\mathrm{m} 2 \mathrm{~s}$ ) and $\mathrm{x}=0.15$. 


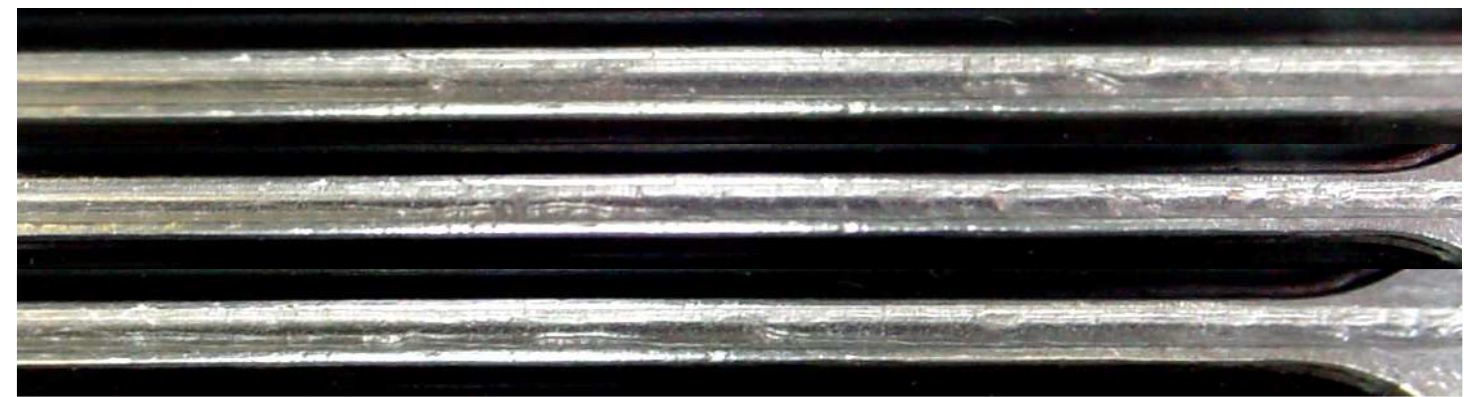

Figure $8(\mathrm{c})$. Flow pattern in test 30 (slug flow), where $\mathrm{G}=123 \mathrm{~kg} /(\mathrm{m} 2 \mathrm{~s})$ and $\mathrm{x}=0.36$.

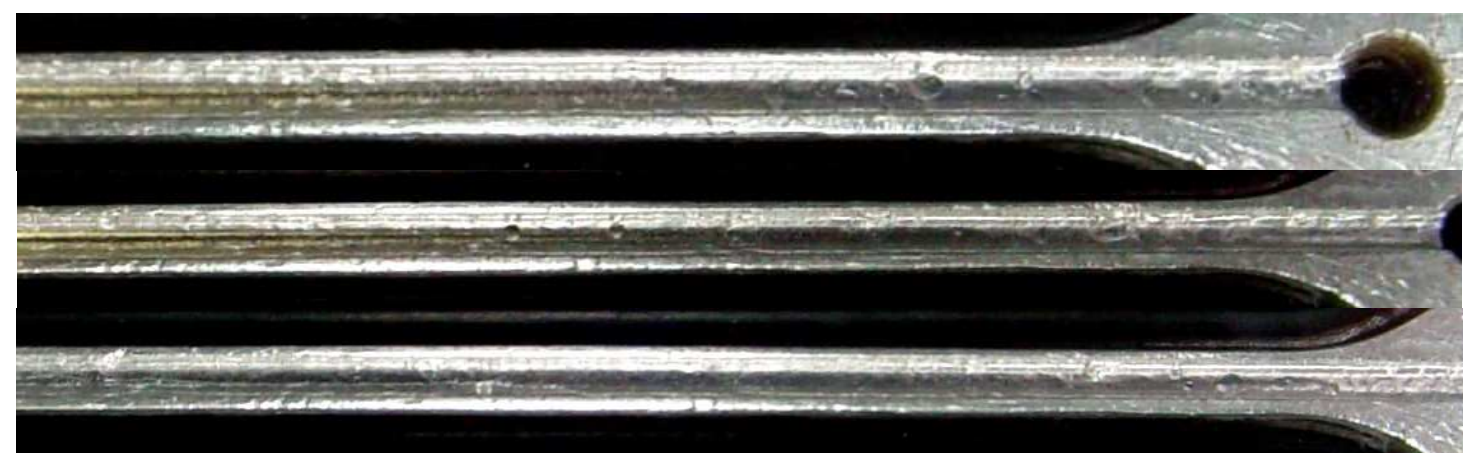

Figure 8(d). Flow pattern in test 31 (annular flow), where $\mathrm{G}=123 \mathrm{~kg} /(\mathrm{m} 2 \mathrm{~s}$ ) and $\mathrm{x}=0.61$.

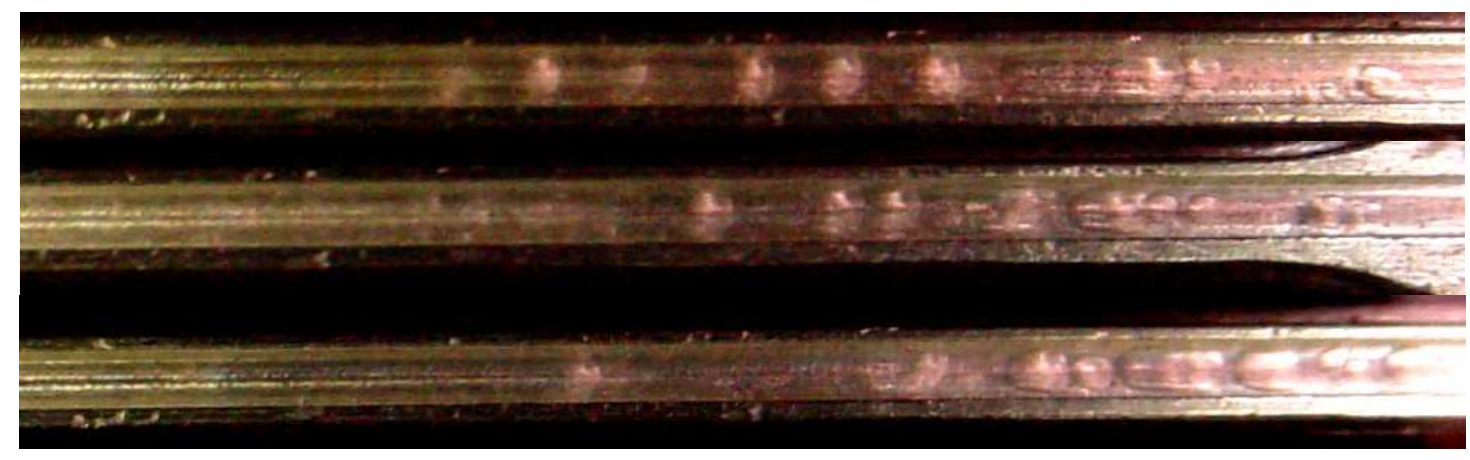

Figure 9(a) .Flow pattern in test 36 (plug flow), where $G=149 \mathrm{~kg} /(\mathrm{m} 2 \mathrm{~s}$ ) and $\mathrm{x}=0.01$.

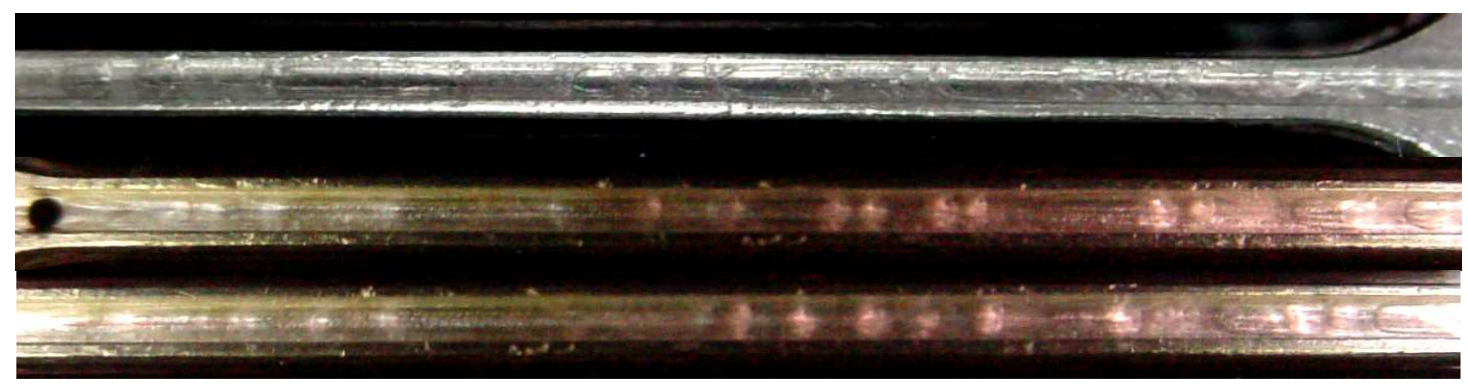

Figure 9(b). Flow pattern in test 40 (plug flow), where $G=149 \mathrm{~kg} /(\mathrm{m} 2 \mathrm{~s}$ ) and $\mathrm{x}=0.13$.

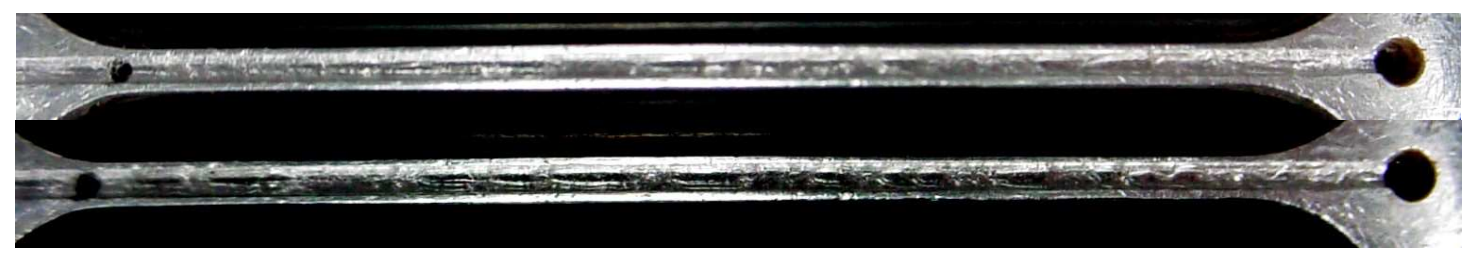

Figure 9(c). Flow pattern in test 41 (plug flow), where $\mathrm{G}=149 \mathrm{~kg} /(\mathrm{m} 2 \mathrm{~s}$ ) and $\mathrm{x}=0.25$. 


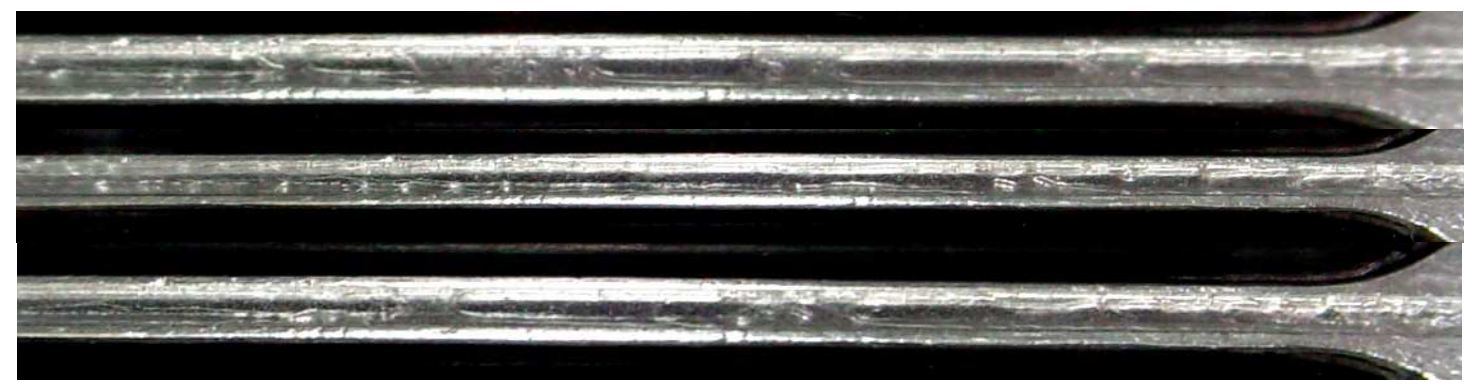

Figure 9(d). Flow pattern in test 43 (slug flow), where $G=149 \mathrm{~kg} /(\mathrm{m} 2 \mathrm{~s})$ and $\mathrm{x}=0.29$.

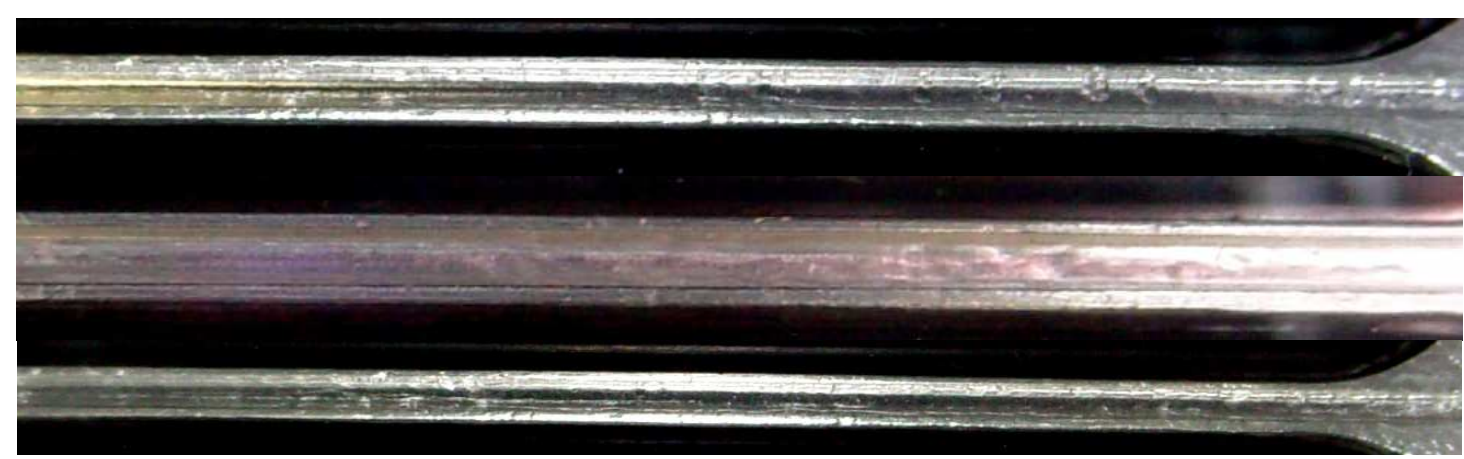

Figure 9(e). Flow pattern in test 45 (slug/annular flow), where $G=149 \mathrm{~kg} /(\mathrm{m} 2 \mathrm{~s})$ and $x=0.50$.

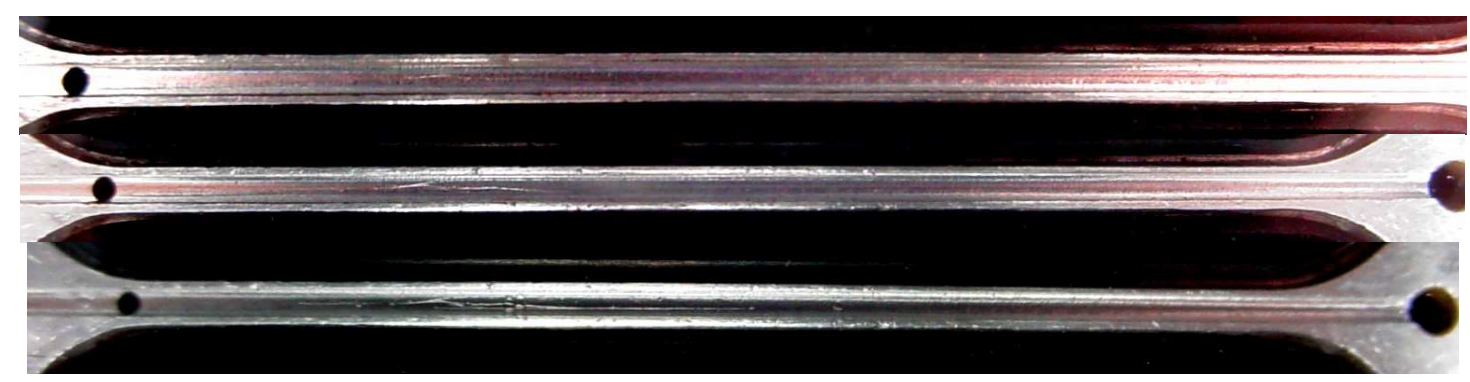

Figure 9(f). Flow pattern in test 46 (annular flow), where $G=149 \mathrm{~kg} /(\mathrm{m} 2 \mathrm{~s}$ ) and $\mathrm{x}=0.73$.

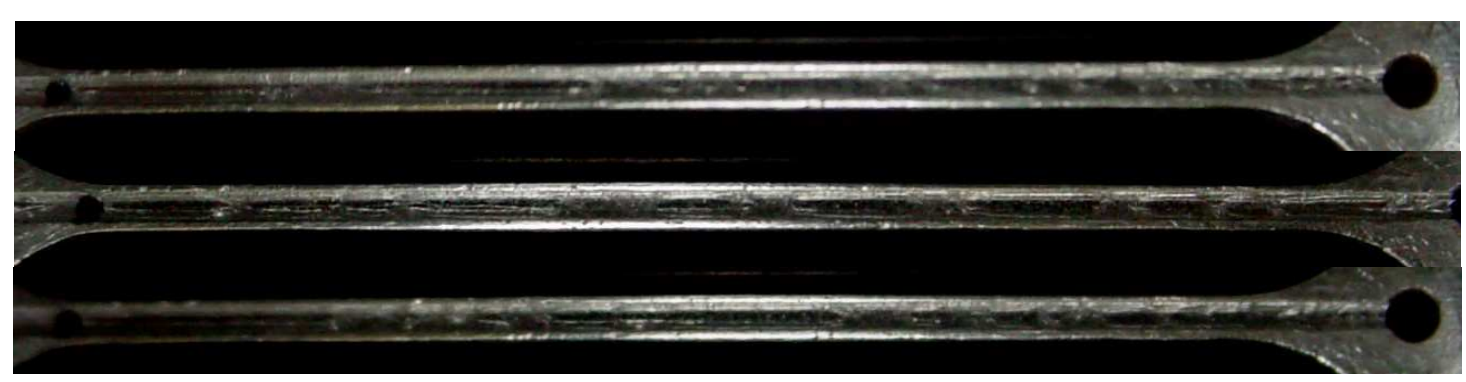

Figure 10(a). Flow pattern in test 50 (slug flow), where $\mathrm{G}=188 \mathrm{~kg} /(\mathrm{m} 2 \mathrm{~s}$ ) and $\mathrm{x}=\mathbf{0 . 1 2}$.

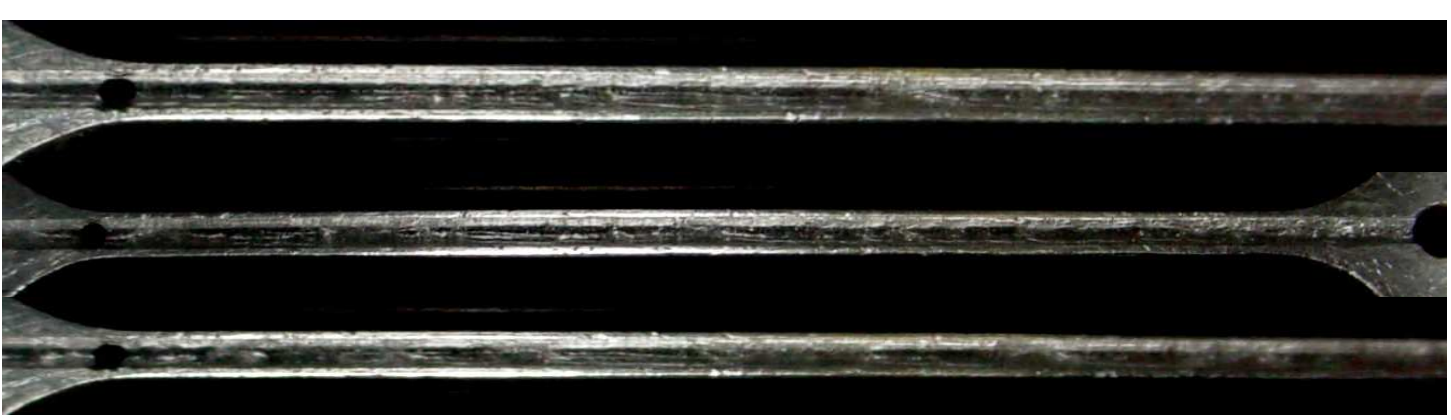

Figure 10(b). Flow pattern in test 52 (slug flow), where $\mathrm{G}=188 \mathrm{~kg} /(\mathrm{m} 2 \mathrm{~s})$ and $\mathrm{x}=0.25$. 


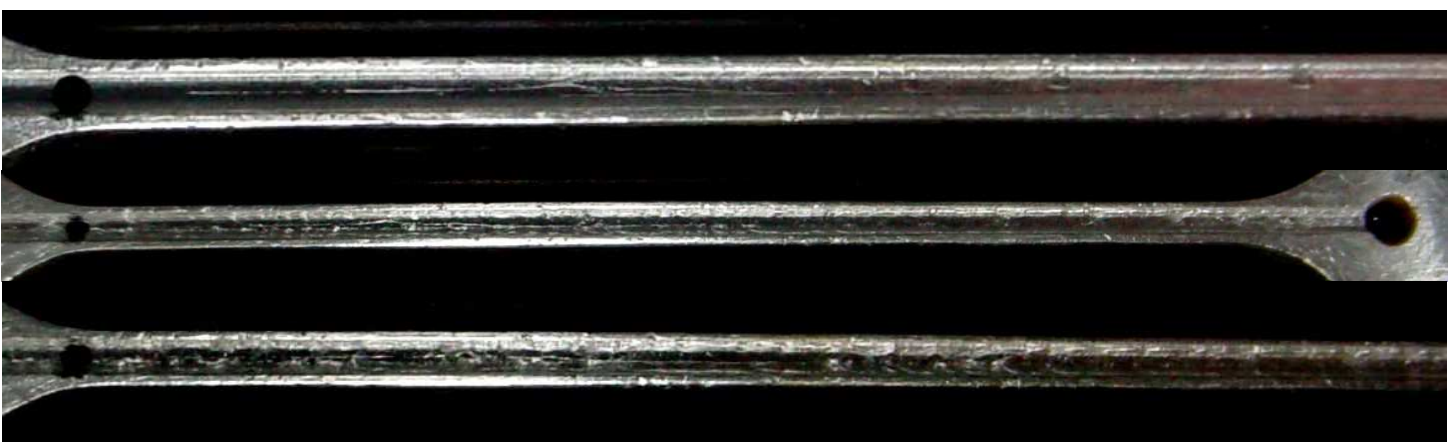

Figure 10(c). Flow pattern in test 54 (slug/annular flow), where $\mathrm{G}=188 \mathrm{~kg} /(\mathrm{m} 2 \mathrm{~s})$ and $\mathrm{x}=\mathbf{0 . 4 5}$.

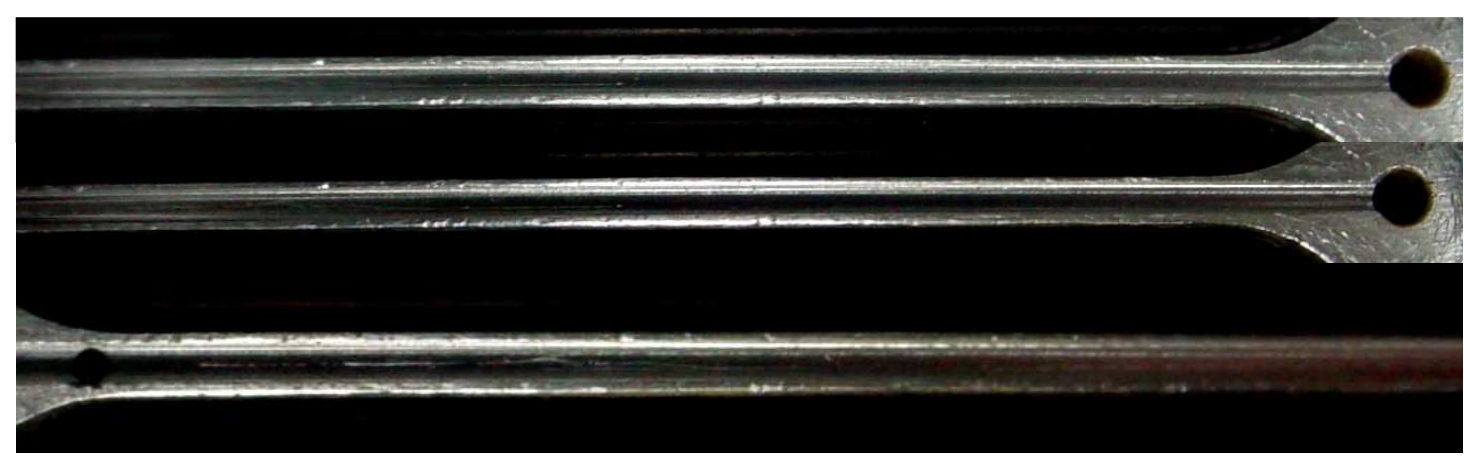

Figure 10(d). Flow pattern in test 55 (annular flow), where $G=188 \mathrm{~kg} /(\mathrm{m} 2 \mathrm{~s})$ and $\mathrm{x}=0.67$.

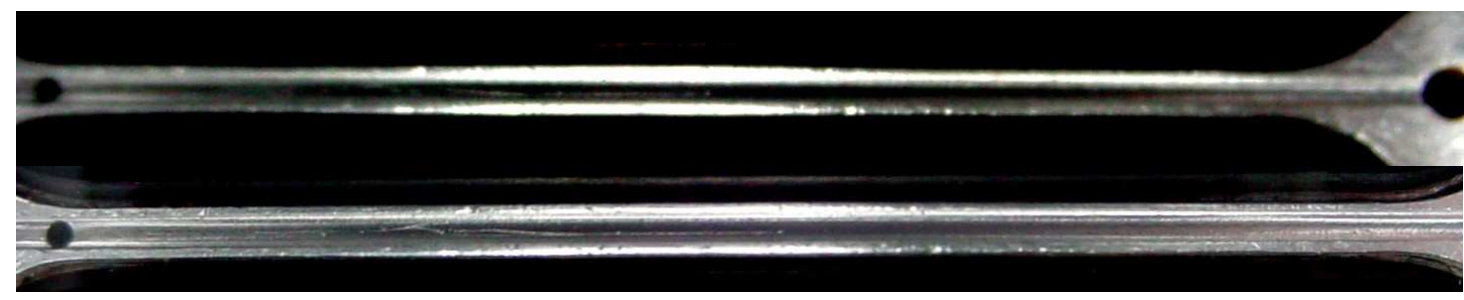

Figure 10(e). Flow pattern in test 56 (annular flow), where $G=188 \mathrm{~kg} /(\mathrm{m} 2 \mathrm{~s}$ ) and $\mathrm{x}=0.79$.

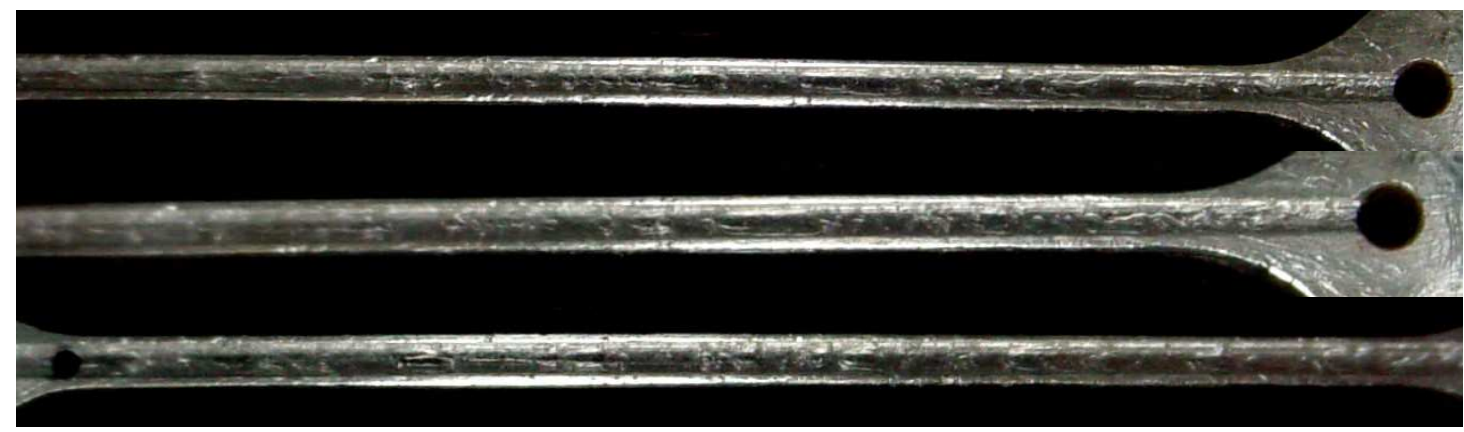

Figure 11(a). Flow pattern in test 58 (slug flow), where $\mathrm{G}=235 \mathrm{~kg} /(\mathrm{m} 2 \mathrm{~s}$ ) and $\mathrm{x}=0.12$.

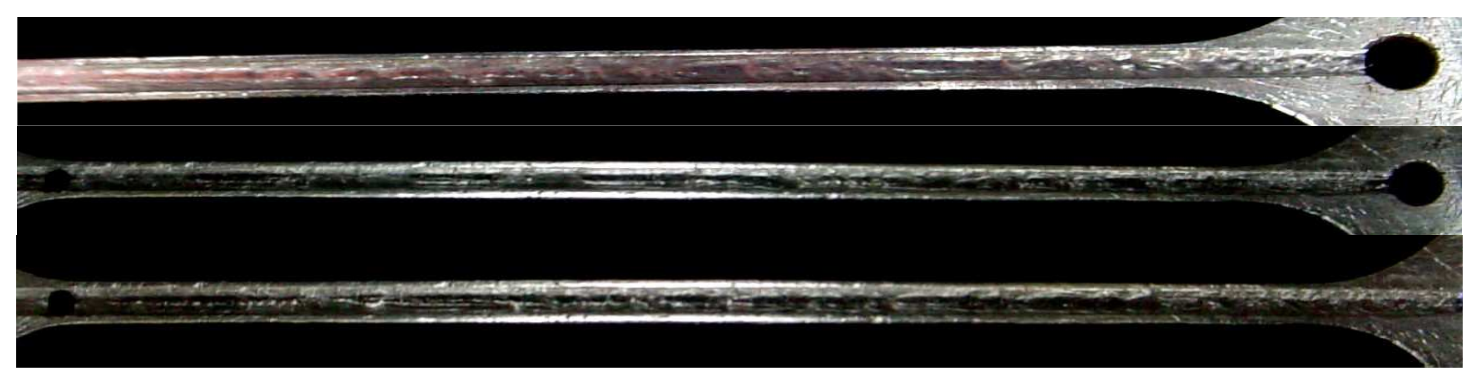

Figure 11(b). Flow pattern in test 59 (slug flow), where $\mathrm{G}=235 \mathrm{~kg} /(\mathrm{m} 2 \mathrm{~s}$ ) and $\mathrm{x}=0.25$. 


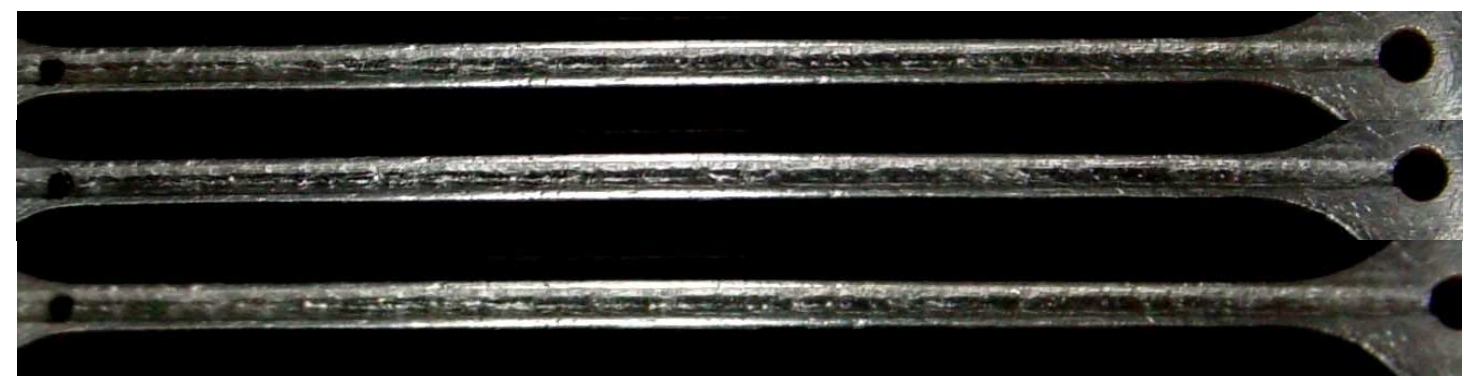

Figure 11(c). Flow pattern in test 62 (slug flow), where $\mathrm{G}=235 \mathrm{~kg} /(\mathrm{m} 2 \mathrm{~s}$ ) and $\mathrm{x}=0.41$.

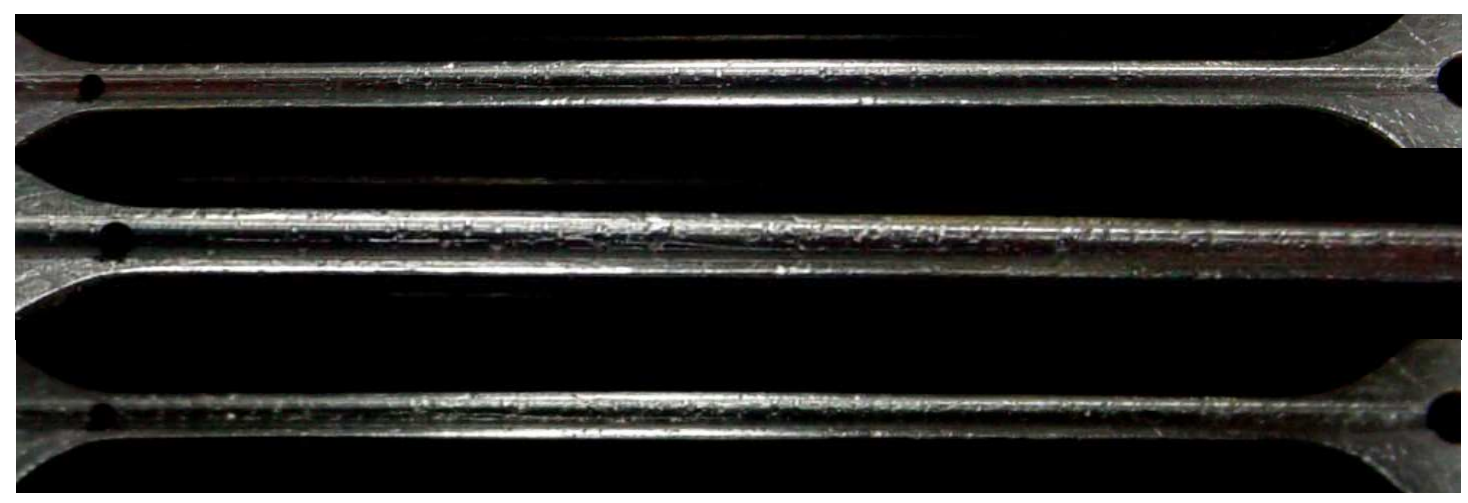

Figure 11(d). Flow pattern in test 63 (annular flow), where $G=235 \mathrm{~kg} /(\mathrm{m} 2 \mathrm{~s})$ and $\mathrm{x}=0.59$.

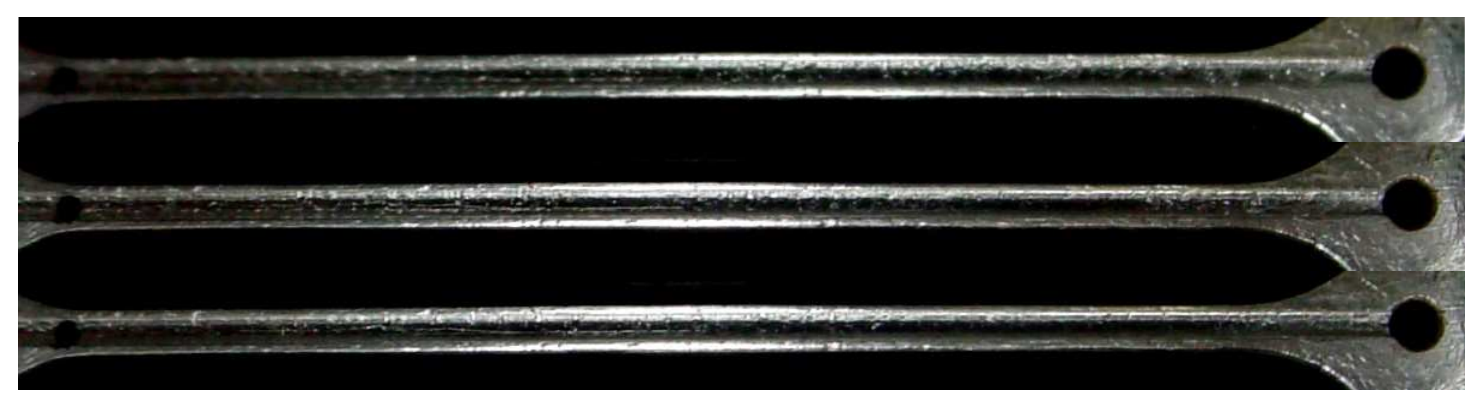

Figure 11(e). Flow pattern in test 65 (annular flow), where $\mathrm{G}=235 \mathrm{~kg} /(\mathrm{m} 2 \mathrm{~s}$ ) and $\mathrm{x}=0.71$.

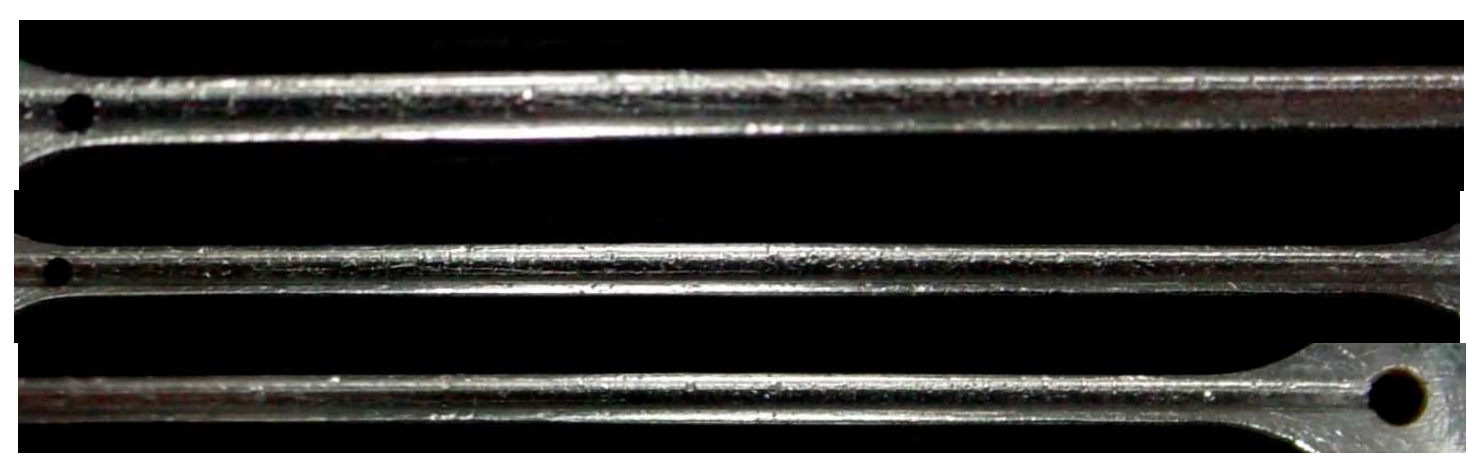

Figure 11(f). Flow pattern in test 66 (annular flow), where $G=235 \mathrm{~kg} /(\mathrm{m} 2 \mathrm{~s}$ ) and $\mathrm{x}=0.81$. 


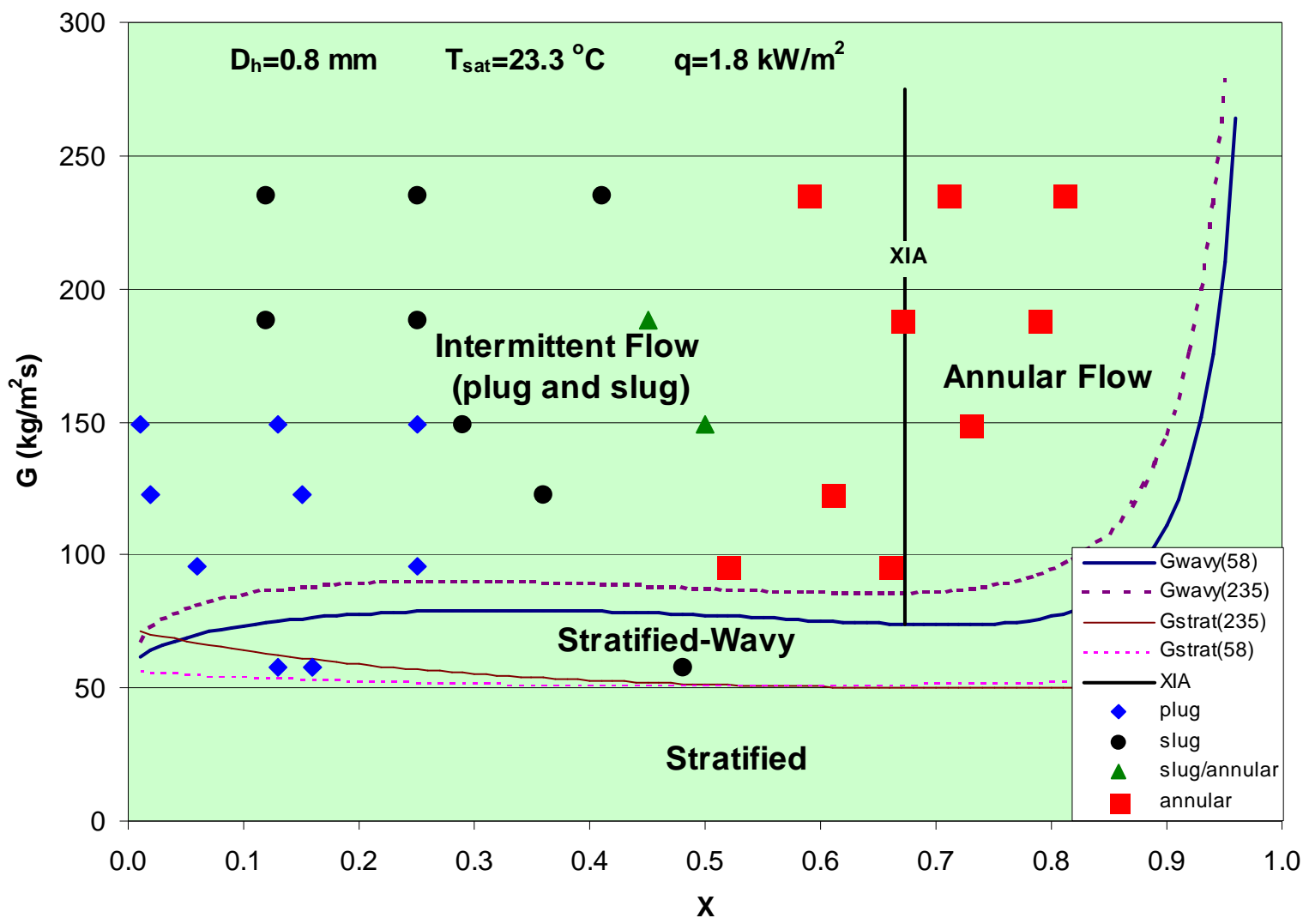

Figure 12. Flow patterns represented on the flow pattern map proposed by Thome and Hajal (2002).

In Fig. 12 the dashed lines were obtained using $\mathrm{G}=235 \mathrm{~kg} /\left(\mathrm{m}^{2} \mathrm{~s}\right)$ while the continuous lines were plotted utilizing $\mathrm{G}=58 \mathrm{~kg} /\left(\mathrm{m}^{2} \mathrm{~s}\right)$. As can be seen in this figure, the flow pattern map proposed by Thome and Hajal (2002) predicts reasonably well the flow patterns obtained for the $\mathrm{CO}_{2}$ evaporation in the microchannel. However, the transition between intermittent flow and annular flow seems to be over predicted on the Thome-Hajal map. It is worth noting that the Thome-Hajal map was tested for tube diameters of 8 and $14 \mathrm{~mm}$, which are much higher than the hydraulic diameter of the microchannel. Therefore, the use of this map for the $\mathrm{CO}_{2}$ evaporation in the microchannel may not be suitable.

\section{Summary and Conclusion}

An experimental study of $\mathrm{CO}_{2}$ evaporation inside a $0.8 \mathrm{~mm}$ hydraulic diameter microchannel is presented in this work. The average heat transfer coefficient along the microchannel was measured and visualization of the flow regimes was conducted. A total of 67 tests were performed at saturation temperatures around $23.3^{\circ} \mathrm{C}$ for one heat flux of $1800 \mathrm{~W} /\left(\mathrm{m}^{2 \circ} \mathrm{C}\right)$. Vapor qualities ranged from 0.005 to 0.88 and mass flux ranged from 58 to $235 \mathrm{~kg} /\left(\mathrm{m}^{2} \mathrm{~s}\right)$. An average heat transfer coefficient of $9700 \mathrm{~W} /\left(\mathrm{m}^{2}{ }^{\circ} \mathrm{C}\right)$ with a standard deviation of $35 \%$ was obtained. The high data scattering did not permit identify a clear dependency of the heat transfer coefficient with the mass flux, as well as with the vapor quality, which seems to characterize nucleate boiling regime for the test conditions. The correlation for nucleate boiling proposed by Gorenflo (1993), with $\mathrm{h}_{\mathrm{o}}=4170 \mathrm{~W} /\left(\mathrm{m}^{2 \circ} \mathrm{C}\right)$, resulted in $\mathrm{h}=8320$ $\mathrm{W} /\left(\mathrm{m}^{2 \circ} \mathrm{C}\right)$, and it was the best comparison to the experimental average result. The dryout of the flow, characterized by the sudden reduction in the heat transfer coefficient, was identified at vapor qualities around 0.85 . Flow visualization results showed three flow regimes. For low vapor qualities (up to about 0.25 ), plug flow was predominant, while slug flow occurred at moderated vapor qualities (from about 0.25 to 0.50 ). Annular flow was the flow pattern for high vapor qualities (above 0.50).

\section{References}

Aldana, J.P., 2000 "Critical Heat Flux of $\mathrm{CO}_{2}$ in a Microchannel at Elevated Subcritical Pressures", MS Thesis, University of Illinois at UrbanaChampaign, Urbana-Champaign, IL, USA, 116p.

Bandarra Filho, E.P. 1997 "Study of Convective Boiling Heat Transfer of Halogened Hydrocarbones Refrigerants in Horizontal Tubes" (In Portuguese), MS Thesis, School of Engineering at São Carlos, University of São Paulo, São Carlos, SP, Brazil, 139 p.

Bandarra Filho, E.P. 2002 "An Experimental Study of Convective Flow Boiling of Refrigerants Inside Smooth and Microfin Tubes" (In Portuguese), Ph.D. Thesis, Engineering School of São Carlos, University of São Paulo, São Carlos, SP, Brazil, 258 p.

Borishanski, V.M., 1969, "Correlation of the Effect of Pressure on the Critical Heat Flux and Heat Transfer Rates Using the Theory of Thermodynamic Similarity", in Problems of Heat Transfer and Hydraulics of Two-Phase Media, Ed. S.S. Kutateladze, pp. 16-37, Pergamon.

Bredesen, A.M., Hafner, A., Pettersen, J., Neksa, P., Aflekt, K., 1997, "Heat Transfer and Pressure Drop for In-tube Evaporation of $\mathrm{CO}_{2}$ ", International Conference on Heat Transfer Issues in Natural Refrigerants, College Park, MD

Carey, V.P., 1992, "Liquid-Vapor Phase-change Phenomena: An Introduction to the Thermophysics of Vaporization and Condensation Processes in Heat Transfer Equipment", Hemisphere Publishing Co.

Cavallini, A., 1996, "Working Fluids for Mechanical Refrigeration", Invited paper presented at the $19^{\text {th }}$ International Congress of Refrigeration, The Hague, August 1995, International Journal of Refrigeration, Vol. 19, $\mathrm{n}^{\circ}$ 8, pp. 485-496.

Cooper, M.G., 1984, "Heat Flow Rates in Saturate Nucleate Pool Boiling - a Wide Ranging Examination Using Reduced Properties", Advances in Heat Transfer, Vol. 16, pp. 157-239.

Gorenflo, D., 1993, "Pool Boiling", In: VDI Heat Atlas (chapter Ha) 
Hihara, E., and Tanaka, S., 2000, "Boiling Heat Transfer of Carbon Dioxide in Horizontal Tubes", Preliminary Proceedings of the IIR Gustav Lorentzen Conference on Natural Working Fluids, Purdue University, W. Lafayette, IN, USA, July, pp. 279-284.

Hogaard Knudsen, H. J., Jensen, P.H., 1997, "Heat Transfer Coefficient for Boiling Carbon Dioxide", IEA/IIR Workshop on $\mathrm{CO}_{2}$ Technologies in Refrigeration, Heat Pump and Air Conditioning Systems, Trondheim, Norway.

Jacobi, A.M., Thome, J.R., 2002, "Heat Transfer Model for Evaporation of Elongated Bubble in Microchannels", Journal of Heat Transfer, n 124, p.1131-1136.

Kandlikar, S.G. 1990, “A General Correlation for Saturated Two-Phase Flow Boiling Heat Transfer Inside Horizontal and Vertical Tubes", Journal of Heat Transfer. Transaction of the ASME, v. 112, p. 219-228.

Koyama, S., Kuwahara, K., Shinmura, E., and Ikeda, S., 2001, "Experimental Study on Flow Boiling of Carbon Dioxide in a Horizontal Small Diameter Tube", IIR Conference on Thermophysical Properties and Transfer Processes of New Refrigerants, October 3-5, Paderborn, Germany. Moffat, R.J., 1988, "Describing the Uncertainties in Experimental

Results", Experimental Thermal and Fluid Science, Vol. 1, pp. 2-17.

Palm, B., 2001, "Heat Transfer in Microchannels", Microscale Thermophysical Engineering, Vol. 5, pp. 155-175.

Pettersen, J., Hafner, A., Skaugen, G., and Rekstad, H., 1998, "Development of Compact Heat Exchangers for $\mathrm{CO}_{2}$ Air-condioning Systems", International Journal of Refrigeration, Vol. 21, n ${ }^{\circ} 3$, pp. 180-193. Pettersen, J. 2001, "Flow Vaporization of $\mathrm{CO}_{2}$ in Microchannels Tubes", Doctor Technicae Thesis. Norwegian University of Science and Technology. Faculty of Mechanical Engineering. Department of Refrigeration and Air Conditioning. 249 pp.
Rieberer, R., 1998, "CO 2 as Working Fluid for Heat Pumps", Revised copy of doctoral thesis submitted to the Faculty of Mechanical Engineering, Graz University of Technology, December.

Sha, M.M. 1982, "Chart Correlation for Saturated Boiling Heat Transfer: Equations and Further Study. ASHRAE Transaction, v. 88, n 1, p. 185-196.

Sun, Z., and Groll, E., 2001, " $\mathrm{CO}_{2}$ Flow Boiling in Horizontal Tubes", Ray W. Herrick Laboratories, Purdue University, Internal Report 229.HL2001-8, W. Lafayette, Indiana, USA, April.

Thome, J.R., 2002, "On Recent Advances in Modelling of Two-phase Flow and Heat Transfer", Proc. $1^{\text {st }}$ International Conference on Heat Transfer, Fluid Mechanics and Thermodynamics, 8-10 April, Kruger Park, South Africa, pp. 27-39.

Thome, J.R., 2004, "Boiling in Microchannels: a Review of Experimental and Theory", International Journal of Heat and Fluid Flow, v. 25, p 128-139.

Thome, J.R. and Hajal, J.E., 2002, "Two-phase Flow Map for Evaporation in Horizontal Tubes: Latest Version", $1^{\text {st }}$ International Conference on Heat Transfer, Fluid Mechanics and Thermodynamics, 8-10 April, Kruger Park, South Africa, pp. 182-188.

Yun, R., Hwang, J.H., Kim, Y.C., and Kim, M.S., 2001, "Evaporation Heat Transfer Characteristics of Carbon Dioxide in a Horizontal Smooth Tube", IIR Conference on Thermophysical Properties and Transfer Processes of New Refrigerants, October 3-5, Paderborn, Germany.

Yun, R., Kim, Y., Kim, M.S., 2005, 'Convective Boiling Heat Transfer Characteristics of $\mathrm{CO}_{2}$ in Microchannels", International Journal of Heat and Mass Transfer, v. 48, p. 235-242.

Zhao, Y., Molki, M., Ohadi, M.M., Dessiatoun, S.V. 2000, "Flow Boiling of $\mathrm{CO}_{2}$ in Microchannels", ASHRAE Transactions: Symposia, Vol. 106, Part 1, pp. 437-445. 